\title{
Genome-wide analyses reveal lineage specific contributions of positive selection and recombination to the evolution of Listeria
} monocytogenes

\author{
Renato H Orsi ${ }^{1}$, Qi Sun ${ }^{2}$ and Martin Wiedmann*1
}

Address: ${ }^{1}$ Department of Food Science, Cornell University, Ithaca, NY, USA and ${ }^{2}$ Computational Biology Service Unit, Cornell University, Ithaca, NY, USA

Email: Renato H Orsi - rho2@cornell.edu; Qi Sun - qisun@tc.cornell.edu; Martin Wiedmann* - mw16@cornell.edu

* Corresponding author

Published: 12 August 2008

BMC Evolutionary Biology 2008, 8:233 doi:10.1 186/147|-2/48-8-233
Received: 26 December 2007

Accepted: 12 August 2008

This article is available from: http://www.biomedcentral.com/I47I-2| 48/8/233

(c) 2008 Orsi et al; licensee BioMed Central Ltd.

This is an Open Access article distributed under the terms of the Creative Commons Attribution License (http://creativecommons.org/licenses/by/2.0), which permits unrestricted use, distribution, and reproduction in any medium, provided the original work is properly cited.

\begin{abstract}
Background: The genus Listeria includes two closely related pathogenic and non-pathogenic species, $L$. monocytogenes and $L$. innocua. $L$. monocytogenes is an opportunistic human foodborne and animal pathogen that includes two common lineages. While lineage $I$ is more commonly found among human listeriosis cases, lineage II appears to be overrepresented among isolates from foods and environmental sources. This study used the genome sequences for one $L$. innocua strain and four $L$. monocytogenes strains representing lineages I and II, to characterize the contributions of positive selection and recombination to the evolution of the $L$. innocualL. monocytogenes core genome.
\end{abstract}

Results: Among the 2267 genes in the L. monocytogenes/L. innocua core genome, 1097 genes showed evidence for recombination and 36 genes showed evidence for positive selection. Positive selection was strongly associated with recombination. Specifically, 29 of the 36 genes under positive selection also showed evidence for recombination. Recombination was more common among isolates in lineage II than lineage I; this trend was confirmed by sequencing five genes in a larger isolate set. Positive selection was more abundant in the ancestral branch of lineage II ( 20 genes) as compared to the ancestral branch of lineage I ( 9 genes). Additional genes under positive selection were identified in the branch separating the two species; for this branch, genes in the role category "Cell wall and membrane biogenesis" were significantly more likely to have evidence for positive selection. Positive selection of three genes was confirmed in a larger isolate set, which also revealed occurrence of multiple premature stop codons in one positively selected gene involved in flagellar motility (flaR).

Conclusion: While recombination and positive selection both contribute to evolution of $L$. monocytogenes, the relative contributions of these evolutionary forces seem to differ by $L$. monocytogenes lineages and appear to be more important in the evolution of lineage II, which seems to be found in a broader range of environments, as compared to the apparently more host adapted lineage I. Diversification of cell wall and membrane biogenesis and motility-related genes may play a particularly important role in the evolution of $L$. monocytogenes. 


\section{Background}

Positive selection and recombination are two evolutionary forces that are clearly important in the evolution of many microorganisms [1-9]. A number of studies of natural bacterial populations have found evidence for positive selection in specific genes, including in Escherichia coli [10], Neisseria meningitides [1,11], and Listeria monocytogenes $[4,9,12]$. Recent whole-genome analyses of E. coli $[6,8]$ and Streptococcus [2] have also confirmed the importance of positive selection during evolution of these pathogens. One study specifically suggested that, in bacteria, up to $2 \times 10^{-5}$ mutations per genome, per generation, are beneficial [5] and another study reported that more than half of the amino acid substitutions between E. coli and Salmonella enterica appear to have been fixed by positive selection [3]. Furthermore, gains in fitness associated with nonsynonymous changes have also been confirmed in in vitro experiments $[13,14]$. Lateral gene transfer (LGT), followed by incorporation of homologous DNA into the genome, appears to be common in many bacteria and occurrence of homologous recombination has been described in many microorganisms $[1,2,4,9,11,15,16]$. Bacterial populations can differ considerably in frequency of recombination though; while some populations appear to be panmictic (e.g., Helicobacter pylori [17]), others seem to show much more limited recombination (e.g., Borrelia burgdorferi [18]).

In absence of recombination, positive selection can be inefficient due to clonal interference and/or genetic load. In the case of "clonal interference", advantageous mutations that arise in different lineages of the same population compete against each other for fixation, which can slow down the fixation of advantageous mutations, and can result in loss of advantageous mutations. "Genetic load" refers to the increase in frequency or fixation in the population of disadvantageous mutations that are linked to advantageous mutations. Recombination not only allows advantageous mutations present in different lineages to be combined and fixed in the same lineage, thus preventing clonal interference [19-23], but also can break the linkage between the advantageous and disadvantageous mutations, thus counteracting "genetic load" [2427]. Positive selection may also play an important role in facilitating maintenance of fragments introduced by recombination in a given population if these fragments confer a selective advantage to the recipient organism.

The genus Listeria includes both mammalian pathogenic species (i.e., L. monocytogenes, a human and animal pathogen and L. ivanovii, an animal pathogen) as well as nonpathogenic species (e.g., L. innocua, L. welshimeri) [28]. L. monocytogenes is a facultative intracellular foodborne pathogen, which can cause severe invasive human disease with case mortality rates of $20 \%$ [29]. Adaptive immunity against L. monocytogenes is believed to be mainly cellularmediated [30], although natural antibodies also seem to play a role in protection $[31,32]$. L. monocytogenes also has the ability to grow under a wide range of environmental stress conditions, including temperatures ranging from $0^{\circ} \mathrm{C}$ to $45^{\circ} \mathrm{C}[33,34], \mathrm{pH}$ ranging from 4 to $9.6[35,36]$ and salt concentration of up to $10 \%$ [37], facilitating its foodborne transmission. L. monocytogenes isolates form a structured population with at least four phylogenetic lineages, including lineages I and II, which are common and lineages IIIA/C and IIIB, which are rare [12,38]. Although isolates from all four lineages have been associated with human listeriosis, most human listeriosis cases and outbreaks have been associated with lineage I isolates, in particular those of serotype $4 \mathrm{~b}[39,40]$. Lineage II isolates, on the other hand, seem to be overrepresented among isolates from foods and environmental sources, and underrepresented among human clinical cases [41,42]. These findings suggest that lineage I isolates are more virulent than lineage II isolates, which has been supported by a risk assessment [43] as well as by observations that lineage I isolates, on average, show higher measures of tissue culture pathogenicity as compared to lineage II isolates $[42,44,45]$. In addition, a considerable proportion of lineage II isolates, but only few lineage I isolates, are virulence-attenuated due to nonsense and frameshift mutations in virulence genes resulting in truncated proteins $[9,46,47]$. Combined, these observations have led to the conclusions that L. monocytogenes lineage I may be host-adapted, while lineage II may represent an environmentally-adapted group [41].

Interestingly, the pathogenic L. monocytogenes is most closely related to the non-pathogenic L. innocua. Consequently, the L. innocua/L. monocytogenes lineage within the genus Listeria has been used as a model system to study the evolution of pathogenicity characteristics, including through comparative genome analyses [48,49]. While gene presence/absence patterns in these two sister species have been probed through both genome sequencing [49] and macroarray [50] studies, facilitating identification of confirmed and putative virulence genes, evolutionary patterns of the core genome of the L. innocua/L. monocytogenes lineage have not yet been comprehensively studied. We used genome sequences available for L. innocua [49] as well as for two L. monocytogenes lineage I and two lineage II strains $[49,51]$ to investigate the contributions of recombination and positive selection to the evolution of the core genome in these Listeria lineages and to gain a better understanding of mechanism that may be important in the evolution of core genome genes during diversification of bacterial pathogens. 


\section{Methods}

\section{Genome data}

Full genome sequence data for four L. monocytogenes isolates and one L. innocua isolate were used for this study (Table 1). Protein and gene sequence data for these five isolates were retrieved from the Comprehensive Microbial Resource [52]. The L. monocytogenes isolates represented two serotype 4b lineage I strains (F2365, H7858) as well as two serotype 1/2a lineage II strains (EGD-e, F6854). While F2365 shows at least 20 authentic mutations resulting in premature stop codons and demonstrates some atypical invasion characteristics [53], the genome for this strain was included in our analyses to provide us with increased power for our analyses and an appropriate number of sequences to perform the lineage specific analyses for positive selection. Genes with premature stop codons were excluded from the analyses for positive selection and recombination; presence of these genes in F2365 thus did not affect our analyses. To identify orthologous genes found in all five genomes (i.e., genes representing members of the L. monocytogenes/L. innocua lineage core genome), the predicted protein sequences of each gene from each genome were clustered using BLAST and TribeMCL [54]. Gene clusters were initially identified using TribeMCL (run with the inflation value set at 2) using BLAST cutoff values of 1e-150, followed by identification of clusters containing less conserved genes (using BLAST cutoff values of $1 e-100,1 e-50$, and $1 e-30)$. This stepwise approach was used to minimize inclusion of multiple genes from the same genome in a given cluster; the majority of the clusters identified had no more than one gene from each genome. Four clusters contained four sequences from each EGD-e, CLIP 11262, F2365, and H7858 as well as two identical or nearly sequences from F6854 (these four sequences were considered paralogs in F6854); only the F6854 sequence that matched the length of the other genes in this cluster was retained. Only clusters containing five sequences, one from each genome, were further analyzed.

Orthologs grouped in the same clusters were aligned using the Clustal W method [55]. Alignments were scanned for frameshift mutations, presence of stop codons, and gene sequences with unequal length; in addition, number of informative sites, average nucleotide diversity $(\pi)$, overall identity, and identity in the first and last 15 nucleotides were obtained for each cluster. Alignments identified as having low identities or containing sequences with different lengths were manually evaluated using the program BioEdit [56] and trimmed or otherwise edited if necessary. If alignments contained frameshift mutations generated by indels (insertion/deletion) followed by another indel that restored the original frame, the alignment was edited by removing the region between the frameshift mutations. Final alignments were used for positive selection and recombination analyses as detailed below.

Each gene cluster was also assigned to one of 19 COGs (Clusters of Orthologous Groups of proteins) or the category "not in COG" based on the EGD-e genome annotation available in the NCBI genome database. The effective number of codons used in a gene (Nc), a measure of the codon bias, was assessed using the program "chips" implemented in the EMBOSS package [57]. Nucleotide diversity and number of informative sites were obtained from PhiPack outputs (see below under "Recombination analyses"). Genes also were classified as encoding (i) cell wall proteins, (ii) secreted proteins or (iii) membrane proteins based on the classifications listed in the LEGER database [58].

\section{Positive selection analysis}

Genes under positive selection were identified using codeml as implemented in PAML version 3.15 [59]. The models implemented in PAML allow for identification of genes under positive selection (as well as specific sites that are under positive selection in a gene) even if the overall $\mathrm{d}_{\mathrm{N}} / \mathrm{d}_{\mathrm{S}}$ ratio $(\omega)$ for a gene is $<1$. We employed two types of tests implemented in PAML to identify genes under positive selection. An overall test for positive selection (Test Overall; TO) was carried out using the null model M1a (Nearly-neutral) and the alternative model M2a (Positive selection) [60]; this test identifies genes under positive selection in any or all of the branches of a given phylogeny. To identify genes that are under positive selection in specific branches of the L. monocytogenes/L. innocua phylogeny, the branch-site test 2 described by Zhang et al. [61] was used. This test was used to identify genes under positive selection in three branches (Fig. 1), including (i)

Table I: Strains and genomes analyzed.

\begin{tabular}{lcccrrr}
\hline \multicolumn{1}{c}{ Strain } & Serotype & Lineage & Species & Genome size (nt) & No. of CDS(I) & Ref. \\
\hline EGD-e & I/2a & II & L. monocytogenes & $2,944,528$ & 2846 \\
F6854 & I/2a & II & L. monocytogenes & $2,953,2 I I$ & {$[49]$} \\
F2365 & 4b & I & L. monocytogenes & $2,905,310$ & {$[5 I]$} \\
H7858 & 4b & I & L. monocytogenes & $2,893,92 I$ & 2821 \\
CLIP II262 & 6a & - & L. innocua & $3,011,209$ & 3007 & {$[5 I]$} \\
\hline
\end{tabular}

(I) number of coding sequences used for cluster analysis. 


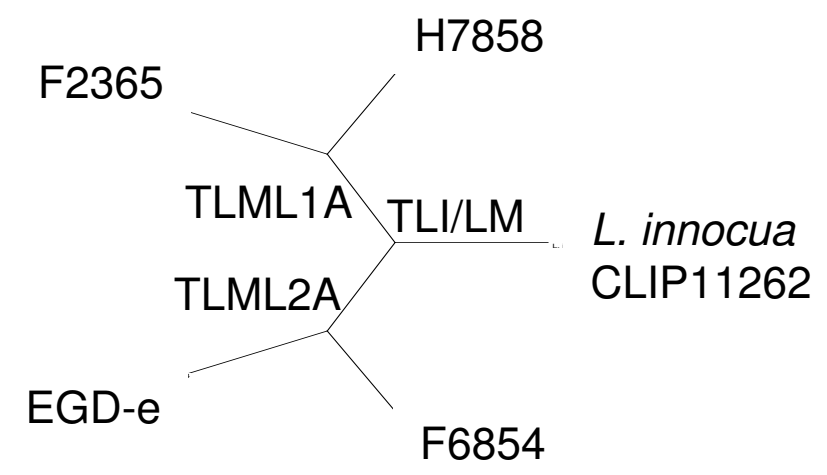

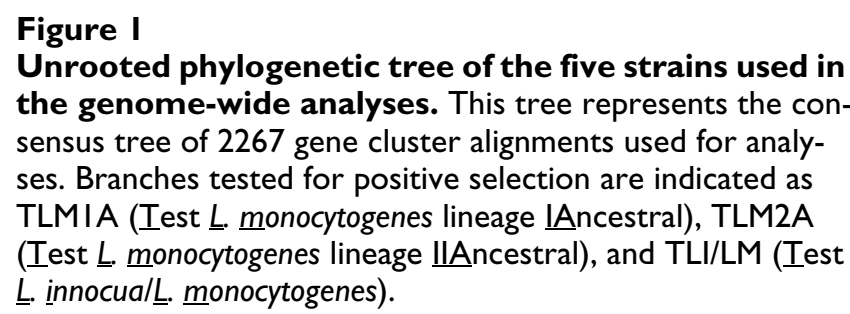

the ancestral branch of L. monocytogenes lineage I (Test $\underline{L}$. monocytogenes lineage IAncestral; TLM1A), (ii) the ancestral branch of $L$. monocytogenes lineage II (Test $\underline{L}$. $\underline{\text { monocy- }}$ togenes lineage IIAncestral; TLM2A), and (iii) the branch separating L. monocytogenes and L. innocua (Test $\underline{L}$. innocua/L. monocytogenes; TLI/LM). Because the sequence of the L. innocua and L. monocytogenes ancestor is unknown, TLI/LM cannot differentiate between positive selection in L. innocua and positive selection in the ancestor of L. monocytogenes. No test was performed to test for evidence of positive selection among genes within a given lineage. Initially, one universal phylogenetic tree (Fig. 1), representing the consensus tree of the 2267 genes analyzed, was used for all PAML analyses. For all genes that were identified as being under positive selection, genespecific trees were constructed and TO and branch-specific PAML analyses were re-run if the gene-specific tree differed from the consensus tree. For eight genes, gene-specific trees differed from the universal tree. PAML analysis with gene-specific trees confirmed positive selection for five genes, while for three genes analyses with the genespecific trees did not find any evidence for positive selection (these genes were thus not considered to be under positive selection).

For each test, nested models (one null model that does not allow for positive selection and one alternative model that allows for positive selection) were compared using a Likelihood Ratio Test (LRT) as described by Yang et al. [62]. For each model, three replicates were generated and the maximum likelihood values for each model were used in the LRT. Genes with negative LRT values were re-run 10 times and the maximum values for each model were used for LRT. Persistent negative LRT values were rounded to zero $(P=1)$. For all branch-specific tests, one degree of freedom was used to calculate $p$-values, while for the overall test, two degrees of freedom were used to calculate $p$ values.

\section{Recombination analyses}

Four tests were used initially to assess gene clusters for evidence of intragenic recombination, including Sawyer's test implemented in GENECONV version 1.81 [63] as well as Neighbor Similarity Score (NSS), Maximum $\chi^{2}$, and the Pairwise Homoplasy Index (PHI), the last three implemented in PhiPack [64]. For GENECONV analyses, the parameter g-scale was set to 1 ; this setting allows polymorphisms within the recombinant fragment, increasing the likelihood of the test to identify ancient recombination events or events where the donated recombinant fragment is similar, but not identical to the recombinant sequence in the alignment. In the GENECONV analyses, only inner fragments were considered. For Maximum $\chi^{2}$, a fixed window size of $2 / 3$ the number of polymorphic sites was used. For PHI, a window size of 50 nucleotides was used. $p$-values were estimated using 10,000 permutations of the alignment for GENECONV and 1,000 permutations for NSS, Maximum $\chi^{2}$ and PHI. Therefore, for all recombination tests, the $p$-values represent the proportion of test statistics of the permuted alignments that were at least as extreme as the observed test statistic.

ClonalFrame version 1.1 [65] was used on selected genes to estimate recombination breakpoints and to help identify the most likely recipients in a given recombination event. ClonalFrame assumes that recombination events generate new polymorphisms in the population and is most useful for data sets where the donor of the recombinant fragment is not present in the data set [65]. Nevertheless, the program can also be used to identify recombination between sequences in the data set, although it might underestimate the amount of recombination in alignments where the donor and recipient are closely related [65]. Analyses were based on two independent runs of the program both using the same settings (100,000 burn-in iteration and data collection for an additional 100,000 iterations; default settings were used for all other parameters). A 95\% consensus tree was obtained from these two runs, and only those branches present in the 95\% consensus tree were analyzed for recombination.

\section{Statistical analyses}

Correction for multiple testing was performed using the procedure reported by Benjamini \& Hochberg [66] as implemented in the program Q-Value [67] with the proportion of expected true null hypotheses set to $1\left(\pi_{0}=1\right)$. 
For each $p$-value, the $q$-value (the expected proportion of false positives among the significant tests) was calculated. Corrections were performed separately for each test (e.g., GENECONV, NSS, etc.; TO, TLI/LM, etc.) to account for testing of multiple genes (i.e., 2237 genes). As the tests used for positive selection are already conservative [61], a false discovery rate (FDR) of $20 \%$ was used for the positives selection analyses. For recombination analyses, an FDR of $10 \%$ was used to compensate the fact that no correction for multiple tests (Sawyer's test, NSS, Maximum $\chi^{2}$ and $\mathrm{PHI}$ ) was carried out due to the high correlation among the tests.

Correlation between COGs and positive selection, recombination, and gene parameters (e.g., gene length, codon bias, nt diversity) were carried out using chi-square tests, Fisher's exact tests, and U-tests implemented in SAS. For association between genes in a given COG category, COGs that were numerically overrepresented among genes under recombination or positive selection were tested for the significance of associations using one-sided tests; Bonferroni corrections were performed based on the number of one-sided tests performed. Significance was set at $5 \%$.

\section{Confirmation of positive selection and recombination patterns in selected genes in a larger isolate population}

To probe whether the positive selection and recombination patterns determined using genome wide analyses on five isolates were representative for larger populations, a diverse set of 40 additional $L$. monocytogenes isolates (Additional file 1) was assembled and used to determine the sequences for five genes (i.e., cheA, phoP, lmo0693, flaR and $l m o 2537$ ) for positive selection and recombination analyses. Isolates were selected to represent the genetic diversity of $L$. monocytogenes, including lineage I (19 isolates), II (13 isolates), IIIA/C (5 isolates), and IIIB (3 isolates), as well as diverse sources (e.g., foods, human clinical cases; see Additional file 1). Experiments with biohazardous materials were approved by the Cornell Institutional Biosafety Committee (MUA \#15520). Nucleotide sequences for these five genes have been deposited in GenBank as alignments (PopSet accession numbers 164520363，164520263，164520173， 164520083, 164519993).

PCR amplification of the five selected genes was carried out using primers and conditions described in Additional file 2. PCR fragments were purified using Exonuclease I $(0.5 \mathrm{U} / \mu \mathrm{l})$ and Shrimp alkaline phosphatase $(0.05 \mathrm{U} / \mu \mathrm{l})$ (USB, NEB) and sequenced (at the Biotechnology Resource Center, Cornell University) using Big Dye Terminator chemistry and AmpliTaq-FS DNA Polymerase and an automated 3730 DNA Analyzer. Sequences were proofread and aligned using Clustal W using Seqman and Meg- align, as implemented in Lasergene 7.2.1. Alignments were used for positive selection and recombination analyses as described above.

\section{Swarming assays}

Swarming assays were performed with six isolates representing each of the six different mutations leading to premature stop codons (i.e., FSL C1-057, FSL F2-649, FSL E1123, FSL F2-663, FSL S4-766 and FSL F2-086), three isolates bearing full length flaR (i.e. 10403S, FSL F2-661 and FSL J1-208), and a non-motile isogenic 10403S $\Delta$ flaA strain [68], which harbors an in-frame deletion of the gene that encodes the flagellin subunit in L. monocytogenes. We furthermore constructed an isogenic in-frame flaR null mutant in L. monocytogenes 10403 S background using Splicing-by-Overlap (SOEing) PCR and allelic exchange, as previously described [69] for use in swarming assays.

Swarming abilities of L. monocytogenes strains were evaluated on semi-soft agar. Strains were initially grown for 24 $\mathrm{h}$ at $37^{\circ} \mathrm{C}$ on BHI agar and colonies were used to stabinoculate BHI semi-soft agar (0.4\%). Swarming ability was assessed by measuring colony area using SigmaScan Pro 5.0 (SPSS Inc., Chicago, IL) for each strain after incubation at room temperature for $48 \mathrm{~h}$. Swarming area for each mutant strain was normalized to the swarming area for strain 10403S, which was set at $100 \%$.

\section{Results \\ Initial identification and characterization of the $L$. monocytogenes/L. innocua core genome}

Using BLAST and TribeMCL (as detailed in the "Methods"), we identified 2267 orthologous genes present in all five genomes, representing an initial definition of the core genome for the L. monocytogenes/L. innocua lineage. The orthologs were highly syntenic in the two $L$. monocytogenes lineages and $L$. innocua (Fig. 2A). The 2267 orthologous genes identified represent $76 \%$ of the coding genes identified in L. innocua CLIP11262 and 80\% of the coding genes identified in L. monocytogenes EGD-e and F2365 (i.e., the two closed L. monocytogenes genomes). Thirty of the 2267 genes in the core genome had $\leq 1$ informative site and were thus not used in subsequent analyses; a final set of 2237 genes was thus used in all genome-wide analyses (shown in green in Fig. 2B).

Genes in COGs "Energy production and conversion", "Amino acid transport and metabolism", "Carbohydrate transport and metabolism", "Replication, recombination and repair", "Defense mechanisms", and "Cell wall/membrane biogenesis" showed a significant tendency to be longer than genes in other COGs (Table 2). Although genes categorized into the COGs "Amino acid transport and metabolism", "General functional prediction", 

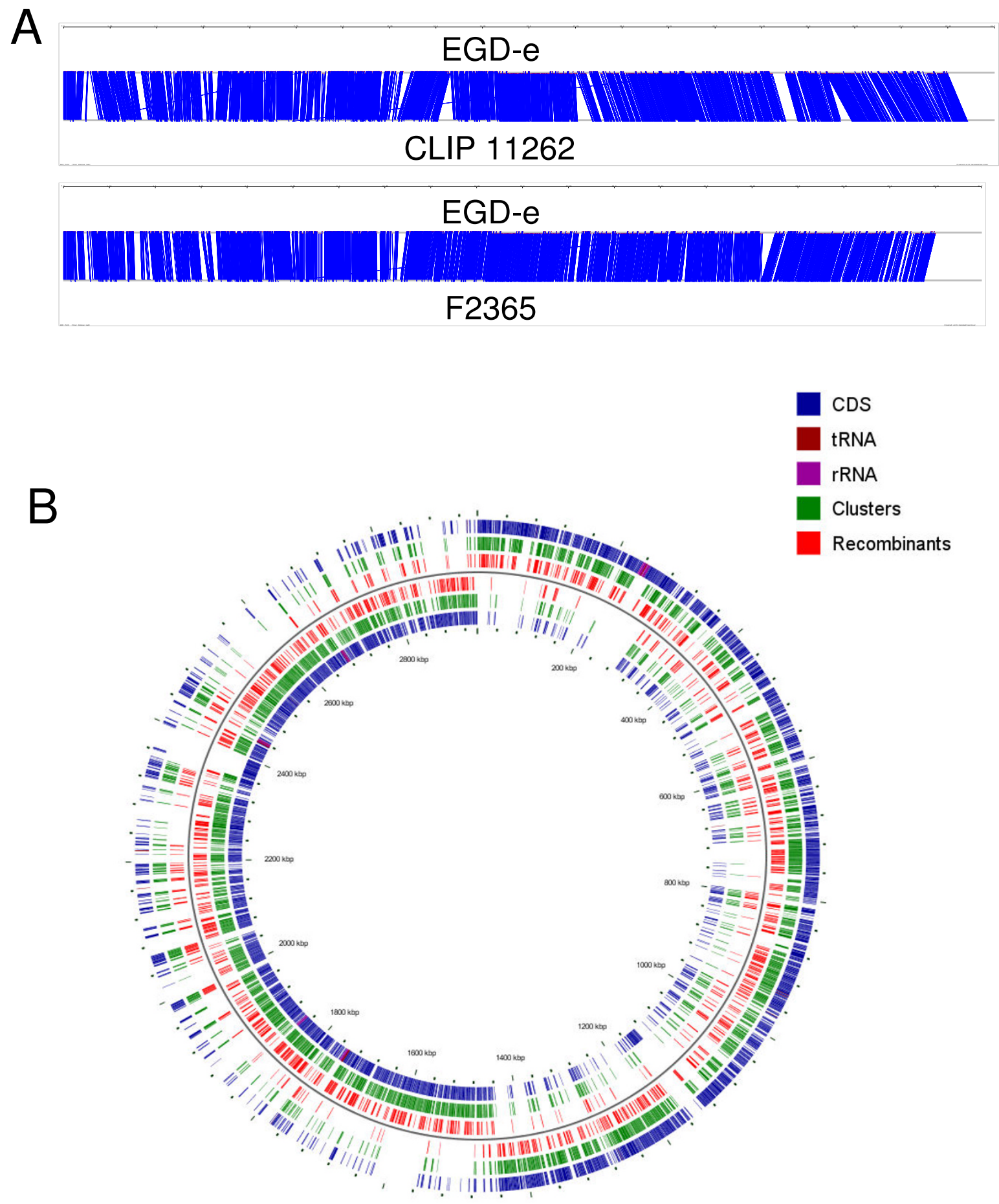

Figure 2

Schematic representations of the genes analyzed including (A) relative position of the orthologs in EGD-e, CLIP II 262 and F2365; and (B) circular chromosome of EGD-e. In "B" all protein coding, tRNA, and rRNA genes are shown in blue, brown, and purple; all genes analyzed are shown in green and genes with evidence for recombination (at least one test significant) are shown in red. There was no evidence for spatial clustering of genes with evidence for recombination $(P$ $=0.957$; U-test). 
Table 2: Associations between COGs and descriptive variables.

\begin{tabular}{|c|c|c|c|c|c|c|}
\hline \multirow[t]{2}{*}{ COG } & \multirow[t]{2}{*}{$\begin{array}{c}\text { Number of gene } \\
\text { analyzed }\end{array}$} & \multicolumn{5}{|c|}{$\begin{array}{l}\text { Bonferroni-corrected } P \text { value for one-sided } U \text {-test testing for associations between } \\
\text { genes in a given COG and }(1)\end{array}$} \\
\hline & & $>$ length & > nt diversity & $\begin{array}{l}>\text { Number of } \\
\text { Informative sites }\end{array}$ & > Codon bias $(2)$ & $<$ Codon bias(2) \\
\hline $\begin{array}{l}\text { Energy production and } \\
\text { conversion }\end{array}$ & 100 & $<0.002$ & ND & NS & 0.007 & ND \\
\hline $\begin{array}{l}\text { Cell cycle control, } \\
\text { mitosis and meiosis }\end{array}$ & 20 & NS & ND & ND & NS & ND \\
\hline $\begin{array}{l}\text { Amino acid transport } \\
\text { and metabolism }\end{array}$ & 181 & $<0.002$ & NS & $<0.002$ & NS & ND \\
\hline $\begin{array}{l}\text { Nucleotide transport } \\
\text { and metabolism }\end{array}$ & 63 & NS & ND & NS & NS & ND \\
\hline $\begin{array}{l}\text { Carbohydrate transport } \\
\text { and metabolism }\end{array}$ & 186 & $<0.002$ & ND & NS & NS & ND \\
\hline $\begin{array}{l}\text { Coenzyme transport } \\
\text { and metabolism }\end{array}$ & 87 & NS & $<0.001$ & 0.004 & ND & 0.047 \\
\hline $\begin{array}{l}\text { Lipid transport and } \\
\text { metabolism }\end{array}$ & 51 & NS & NS & NS & NS & ND \\
\hline Translation & 91 & NS & ND & ND & $<0.001$ & ND \\
\hline Transcription & 187 & ND & ND & ND & ND & $<0.002$ \\
\hline $\begin{array}{l}\text { Replication, } \\
\text { recombination and } \\
\text { repair }\end{array}$ & 92 & $<0.002$ & $<0.001$ & $<0.002$ & ND & NS \\
\hline $\begin{array}{l}\text { Cell wall/membrane } \\
\text { biogenesis }\end{array}$ & 76 & $<0.002$ & $<0.001$ & $<0.002$ & NS & ND \\
\hline Cell motility & 40 & NS & ND & NS & ND & NS \\
\hline $\begin{array}{l}\text { Posttranslational } \\
\text { modification, protein } \\
\text { turnover, chaperones }\end{array}$ & 52 & ND & ND & ND & 0.021 & ND \\
\hline $\begin{array}{l}\text { Inorganic ion transport } \\
\text { and metabolism }\end{array}$ & 104 & NS & ND & NS & ND & NS \\
\hline $\begin{array}{l}\text { Secondary metabolites } \\
\text { biosynthesis, transport } \\
\text { and catabolism }\end{array}$ & 31 & ND & NS & NS & ND & NS \\
\hline $\begin{array}{l}\text { General function } \\
\text { prediction only }\end{array}$ & 254 & NS & NS & 0.008 & ND & NS \\
\hline Function unknown & 161 & ND & NS & ND & ND & NS \\
\hline $\begin{array}{l}\text { Signal transduction } \\
\text { mechanisms }\end{array}$ & 104 & NS & ND & NS & ND & $<0.002$ \\
\hline $\begin{array}{l}\text { Intracellular trafficking } \\
\text { and secretion }\end{array}$ & 37 & NS & ND & ND & NS & ND \\
\hline Defense mechanisms & 51 & $<0.002$ & NS & 0.020 & ND & NS \\
\hline Not in COGs & 511 & ND & ND & ND & ND & NS \\
\hline
\end{tabular}

(I) ">" or "<" indicates the direction of the one-sided tests (i.e. column "> Codon bias" shows Bonferroni-corrected p-values for associations between genes in a given COG and higher codon bias (as compared to the genes in other COGs), while the column "< Codon bias" test shows Bonferroni-corrected $p$-values for genes in COGs with lower codon bias as compared to genes in other COGs; "ND" = Not determined (tests were not performed for COGs that showed values that were not consistent with the tested alternative hypothesis, e.g., if the average gene length for genes in a given COG was below average than we did not test for an association of this COG with increased gene length); "NS". Not significant. (2)Tests for codon bias were performed using Nc values; a lower Nc indicates increased codon bias.

"Defense mechanisms", "Coenzyme transport and metabolism", "Replication, recombination and repair", and "Cell wall/membrane biogenesis" showed a significant tendency for a greater number of informative sites than the genes in other COGs (Table 2), only genes in the last three COGs showed a significant tendency for a higher average genetic diversity $(\pi)$ (Table 2 ).
Genes categorized into the COGs "Energy production and conversion", "Translation", and "Posttranslational modification, protein turnover, chaperone" showed a significant tendency for a higher codon bias (Table 2), possibly reflecting their housekeeping roles and higher expression rates [70-72]. Conversely, genes in the COGs "Coenzyme transport and metabolism", "Transcription", and "Signal 
transduction mechanisms" showed a tendency for lower codon bias (Table 2), possibly because these genes are not constitutively expressed and are not highly expressed in the cell, lowering the constraint for preferential codons usage [70-72].

\section{$A$ considerable number of $L$. monocytogenes and $L$. innocua genes show evidence for recombination}

Among the 2237 orthologs tested, 1097 genes (representing approx. $49 \%$ of the genes in the L. monocytogenes $/ L$. innocua core genome) showed significant evidence (FDR < $10 \%$ ) for recombination in at least one of the four recombination tests used (these genes are shown in red in Fig. 2b). GENECONV, NSS, Maximum $\chi^{2}$ and PHI identified $508,460,900$, and 252 orthologs, respectively, with significant evidence for recombination. A total of 516, 282, 156, and 143 orthologs showed significant evidence for recombination in one, two, three and all four tests, respectively. Genes with evidence for recombination showed a tendency to have longer alignments $(P<0.001$; One-sided U-Test $)$, lower codon bias $(P=0.013)$, higher nucleotide diversity $(P<0.001)$, and more informative sites $(P<$ $0.001)$ then genes with no evidence for recombination. These findings are consistent with the expectation that, by chance, shorter genes are less likely to be involved in intragenic recombination, but also the observation that shorter sequences provides less power in the analyses for evidence of recombination $[64,73]$.

When genes that encode for (i) cell wall proteins, (ii) secreted proteins or (iii) membrane proteins (based on the listings in LEGER) were tested for their prevalence among genes with evidence for recombination, these three genes classes (i.e., cell wall proteins, secreted proteins, and membrane proteins) were under-represented $(P$ $=0.002, P=0.001$, and $P=0.013$, respectively; one-sided Fisher's exact test) among the 1097 genes with significant evidence for recombination, suggesting that these genes are less likely to have experienced recombination.

Genes in three COGs are overrepresented among the genes that show evidence for a history of recombination (Table 3). For example, the "Carbohydrate transport and metabolism" COG was significantly overrepresented among the 1097 genes with evidence for recombination in at least one of the four tests $(P=0.012)$. Genes in this COG were also significantly more likely to have low $p$-values (indicative of significant evidence for recombination) as compared to genes in the other COGs for each of the four tests (as determined by U-tests; see Table 3). For three tests (NSS, Maximum $\chi^{2}$, and PHI), genes in the "Amino acid transport and metabolism" COG were significantly more likely to have low $p$-values (indicative of significant evidence for recombination), as compared to genes in the other COGs, respectively (Table 3 ). These data may indicate that recombination allows $L$. monocytogenes and $L$. innocua to rapidly generate and acquire diversity in genes involved in carbohydrate and amino acid transport and metabolism, which may facilitate adaptation to environments that differ in nutrient availability (e.g., host and non-host associated environments). As these two COGs also showed a tendency to have longer genes, the association between these COGs and recombination could also be due to an increased power to detect recombination.

Thirty-six L. monocytogenes and L. innocua genes show evidence for positive selection

PAML identified 36 genes under positive selection (FDR < $20 \%$ ) with either the overall test (TO) or the branch specific tests, including one gene (lmo2178) identified with two branch specific tests and one gene (lmo0782) identified with $\mathrm{TO}$ and two branch specific tests (Table 4). Three genes were identified as being under positive selection with the overall test (TO). Seven were identified with the L. innocua test (TLI/LM), 9 with the L. monocytogenes lineage I ancestor test (TLM1A), and 20 with the L. monocytogenes lineage II ancestor test (TLM2A). Genes under positive selection showed a tendency to have more informative sites and to be longer than genes not under positive selection $(P=0.001$ and $P=0.031$; one-sided $U$ Test), probably as these two factors may increase the power of the test for positive selection. Positive selection was not associated with nucleotide diversity or codon bias.

Table 3: Association between COGs and recombination

\begin{tabular}{|c|c|c|c|c|c|}
\hline \multirow[t]{2}{*}{ COG } & \multirow{2}{*}{$\begin{array}{l}P \text {-values for association with } \\
\text { recombination }(1)\end{array}$} & \multicolumn{4}{|c|}{ P-values for association with recombination test ${ }^{(2)}$} \\
\hline & & GENECONV & NSS & Maximum $\chi^{2}$ & PHI \\
\hline Carbohydrate transport and metabolism & 0.012 & 0.001 & $<0.001$ & 0.014 & 0.032 \\
\hline Amino acid transport and metabolism & NS & NS & 0.001 & 0.026 & 0.002 \\
\hline Defense mechanisms & NS & NS & 0.022 & NS & NS \\
\hline
\end{tabular}

(1) Fisher's exact test with Bonferroni correction; NS = not significant;

(2) U-test with Bonferroni correction. 
Table 4: Genes under positive selection.

\begin{tabular}{|c|c|c|c|c|c|c|c|c|}
\hline Gene locus & $\begin{array}{l}\text { Gene description } \\
\text { (gene symbol) }\end{array}$ & COG(I) & $\begin{array}{l}\text { Recombina- } \\
\text { tion(2) }\end{array}$ & $\begin{array}{l}\text { Branch under } \\
\text { pos. selection }\end{array}$ & Q-value & $\omega^{(3)}$ & $p^{(4)}$ & BEB $(P>95 \%)^{(5)}$ \\
\hline Lmo0098 & $\begin{array}{l}\text { PTS system, mannose/ } \\
\text { fructose/sorbose family, } \\
\text { IID component (mptD) }\end{array}$ & NCOG & GCV; MAX & LI/LM & 0.170 & 472.58 & 0.004 & - \\
\hline Lmo0099 & $\begin{array}{c}\text { conserved hypothetical } \\
\text { protein }\end{array}$ & NCOG & - & LI/LM & 0.170 & $\infty$ & 0.009 & - \\
\hline Lmo0I39 & $\begin{array}{l}\text { conserved hypothetical } \\
\text { protein }\end{array}$ & NCOG & - & LM2A & 0.160 & 56.74 & 0.054 & 95 \\
\hline Lmo0297 & $\begin{array}{c}\text { PRD/PTS system IIA } 2 \\
\text { domain protein }\end{array}$ & K; G; T & $\begin{array}{l}\text { GCV; MAX; NSS; } \\
\text { PHI }\end{array}$ & LM2A & 0.164 & $\infty$ & 0.012 & 499 \\
\hline Lmo0397 & $\begin{array}{l}\text { conserved hypothetical } \\
\text { protein }\end{array}$ & $\mathrm{S}$ & GCV; MAX & LM2A & 0.1264 & $\infty$ & 0.043 & - \\
\hline Lmo0429 & $\begin{array}{l}\text { glycosyl hydrolase, family } \\
38\end{array}$ & G & $\begin{array}{l}\text { GCV; MAX; NSS; } \\
\text { PHI }\end{array}$ & LM2A & 0.0325 & 977.51 & 0.008 & 667 \\
\hline Lmo0455 & $\begin{array}{l}\text { conserved hypothetical } \\
\text { protein }\end{array}$ & $\mathrm{T} ; \mathrm{Q}$ & $\begin{array}{l}\text { GCV; } \underset{P A X ; N S S ;}{\text { PHI }} \\
\end{array}$ & LM2A & 0.1214 & $\infty$ & 0.004 & - \\
\hline Lmo0653 & $\begin{array}{l}\text { conserved hypothetical } \\
\text { protein }\end{array}$ & $\mathrm{S}$ & MAX & LM2A & 0.033 & $\infty$ & 0.012 & 306 \\
\hline Lmo0658 & $\begin{array}{c}\text { endonuclease III domain } \\
\text { protein }\end{array}$ & $L$ & MAX; NSS & LM2A & 0.108 & $\infty$ & 0.023 & 209 \\
\hline Lmo0692 & $\begin{array}{c}\text { chemotaxis protein CheA } \\
\text { (cheA) }\end{array}$ & $\mathrm{T} ; \mathrm{N}$ & $\begin{array}{l}\text { GCV; MAX; NSS; } \\
\text { PHI }\end{array}$ & LMIA & 0.156 & $\infty$ & 0.002 & - \\
\hline Lmo0693 & $\begin{array}{l}\text { flagellar motor switch } \\
\text { domain protein }\end{array}$ & $\mathrm{N} ; \mathrm{U}$ & - & LM2A & 0.007 & $\infty$ & 0.022 & - \\
\hline Lmo0695 & $\begin{array}{c}\text { conserved hypothetical } \\
\text { protein }\end{array}$ & NCOG & MAX; NSS; PHI & LMIA & 0.175 & $\infty$ & 0.014 & - \\
\hline Lmo0732 & $\begin{array}{l}\text { cell wall surface anchor } \\
\text { family protein }\end{array}$ & NCOG & GCV & LMIA & 0.185 & 6.92 & 0.076 & - \\
\hline \multirow[t]{3}{*}{ Lmo0782 } & $\begin{array}{l}\text { PTS system, mannose/ } \\
\text { fructose/sorbose family, } \\
\text { IIC component (mpoD) }\end{array}$ & NCOG & GCV; MAX & Overall; & 0.146 & 88.23 & 0.008 & - \\
\hline & & & & LMIA; & 0.052 & $\infty$ & 0.000I; & - \\
\hline & & & & LM2A & 0.098 & $\infty$ & 0.004 & - \\
\hline Lmo0785 & $\begin{array}{l}\text { sigma-54 dependent } \mathrm{Kal} \\
\text { regulator }(\operatorname{manR})\end{array}$ & $\mathrm{K} ; \mathrm{T}$ & GCV; MAX & LM2A & 0.129 & 1.00 & 0.000 & - \\
\hline Lmo0872 & $\begin{array}{l}\text { major facilitator family } \\
\text { transporter }\end{array}$ & G & GCV; MAX; NSS & LM2A & 0.137 & $\infty$ & 0.008 & - \\
\hline Lmo0910 & $\begin{array}{l}\text { putative membrane } \\
\text { protein }\end{array}$ & $\mathrm{R}$ & MAX; NSS & LMIA & 0.019 & $\infty$ & 0.012 & - \\
\hline Lmol I46 & $\begin{array}{l}\text { conserved hypothetical } \\
\text { protein }\end{array}$ & NCOG & GCV; MAX & LI/LM & 0.046 & 223.37 & 0.023 & 169 \\
\hline Lmol I64 & PduO protein $(p d u O)$ & S; R & GCV & LI/LM & 0.170 & 195.87 & 0.038 & - \\
\hline Lmol4I2 & $\begin{array}{l}\text { DNA topology modulation } \\
\text { protein FlaR (flaR) }\end{array}$ & $\mathrm{F}$ & - & LM2A & 0.160 & 8.56 & 0.139 & $12 ; 37 ; 68$ \\
\hline Lmol424 & $\begin{array}{l}\text { transporter, NRAMP } \\
\text { family }(m n t H)\end{array}$ & $P$ & GCV & LMIA & 0.185 & 1.00 & 0.000 & - \\
\hline Lmol 523 & $\begin{array}{l}\text { GTP pyrophosphokinase } \\
(\text { relA })\end{array}$ & $\mathrm{K} ; \mathrm{T}$ & - & LM2A & 0.033 & 1.00 & 0.000 & - \\
\hline Lmol 529 & $\begin{array}{c}\text { preprotein translocase, } \\
\text { YajC subunit }\end{array}$ & $\cup$ & - & LI/LM & 0.170 & $\infty$ & 0.011 & - \\
\hline Lmo2102 & $\begin{array}{c}\text { glutamine } \\
\text { amidotransferase, SNO } \\
\text { family }(p d x T)\end{array}$ & $\mathrm{H}$ & $\begin{array}{l}\text { GCV; } \\
\text { PHAX; NSS; }\end{array}$ & LMIA & 0.185 & $\infty$ & 0.017 & 66 \\
\hline Lmo2I2I & $\begin{array}{l}\text { glycosyl transferase, family } \\
65\end{array}$ & G & GCV; MAX; NSS & LMIA & $7.6 \mathrm{E}-06$ & 35.31 & 0.031 & $\begin{array}{c}722 ; 723 ; 725 ; 729 ; \\
730 ; 744 ; 752 ;\end{array}$ \\
\hline \multirow[t]{2}{*}{ Lmo2I78 } & $\begin{array}{l}\text { cell wall surface anchor } \\
\text { family protein }\end{array}$ & $M$ & $\begin{array}{l}\text { GCV; MAX; NSS; } \\
\text { PHI }\end{array}$ & LI/LM; & 0.193 & 15.92 & 0.001 & - \\
\hline & & & & LM2A & 0.137 & 5.34 & 0.025 & 1769 \\
\hline Lmo22I5 & $\begin{array}{l}\text { ABC transporter, ATP- } \\
\text { binding protein }\end{array}$ & $\mathrm{V}$ & MAX; NSS & Overall & 0.188 & 14.23 & 0.008 & - \\
\hline Lmo2222 & $\begin{array}{l}\text { Ser/Thr protein } \\
\text { phosphatase family protein }\end{array}$ & $L$ & GCV; MAX & LM2A & 0.160 & $\infty$ & 0.021 & 253 \\
\hline
\end{tabular}


Table 4: Genes under positive selection. (Continued)

\begin{tabular}{|c|c|c|c|c|c|c|c|c|}
\hline Lmo2446 & $\begin{array}{c}\text { glycosyl hydrolase, family } \\
31\end{array}$ & G & $\begin{array}{l}\text { GCV; MAX; NSS; } \\
\text { PHI }\end{array}$ & LM2A & 0.003 & $\infty$ & 0.0001 & - \\
\hline Lmo2596 & ribosomal protein S9 (rpsl) & NCOG & - & LM2A & 0.021 & $\infty$ & 0.010 & - \\
\hline Lmo26II & adenylate kinase (adk) & $\mathrm{F}$ & GCV; MAX & LM2A & 0.120 & 24.80 & 0.013 & - \\
\hline Lmo2724 & $\begin{array}{c}\text { conserved hypothetical } \\
\text { protein }\end{array}$ & $S$ & NSS & LI/LM & 0.170 & $\infty$ & 0.008 & - \\
\hline Lmo2802 & $\begin{array}{c}\text { glucose-inhibited division } \\
\text { protein B (girB) }\end{array}$ & $M$ & $\begin{array}{l}\text { GCV; MAX; NSS; } \\
\text { PHI }\end{array}$ & LMIA & 0.046 & $\infty$ & 0.013 & - \\
\hline Lmo2804 & $\begin{array}{l}\text { conserved hypothetical } \\
\text { protein }\end{array}$ & NCOG & $\begin{array}{l}\text { GCV; MAX; NSS; } \\
\text { PHI }\end{array}$ & Overall & $6.5 \mathrm{E}-17$ & 16.53 & 0.044 & - \\
\hline Lmo2824 & $\begin{array}{l}\text { D-isomer specific 2- } \\
\text { hydroxyacid } \\
\text { dehydrogenase family } \\
\text { protein }\end{array}$ & $\mathrm{E} ; \mathrm{H}$ & GCV; MAX; NSS & LM2A & 0.160 & 229.62 & 0.003 & - \\
\hline
\end{tabular}

(I) NCOG: Not in COGs; K: Transcription; G: Carbohydrate transport and metabolism; T: Signal transduction mechanisms; S: Function unknown; Q: Secondary metabolites biosynthesis, transport and catabolism; L: Replication, recombination and repair; N: Cell motility; U: Intracellular trafficking and secretion; R: General function prediction only; F: Nucleotide transport and metabolism; P: Inorganic ion transport and metabolism; E: Amino acid transport and metabolism; $\mathrm{H}$ : Coenzyme transport and metabolism; M: Cell wall/membrane biogenesis; V: Defense mechanisms (2) GCV: GENECONV; MAX: Maximum $\chi^{2}$; NSS: Neighbour Similarity Score; PHI: Pairwise Homoplasy Test

(3) $\omega=d_{N} / d_{S}$ (Number of nonsynonymous changes per nonsynonymous sites/Number of synonymous changes per synonymous sites); infinite values of $\omega(\infty)$ indicate that the model did not find synonymous changes for the branches tested $\left(d_{S}=0 ; \omega \sim \infty\right)$. However, this (i.e., $\left.\omega \sim \infty\right)$ does not affect the validity of the Likelihood Ratio Test, which was used to identify the genes under positive selection (Z. Yang, pers. Communication; see

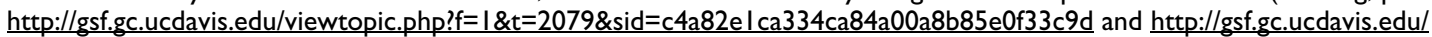
viewtopic.php? $\mathrm{f}=\mid$ \& $\mathrm{t}=2329 \& \mathrm{sid}=\mathrm{c} 4 \mathrm{a} 82 \mathrm{e}$ l ca334ca84a00a8b85e0f33c9d;

(4) Proportion of sites under positive selection

(5) This column lists sites identified using Bayes Empirical Bayes (BEB) as being under positive selection; numbers identify the amino acid sites (in alignments) that are under positive selection

While eight of the genes under positive selection (i.e., Imo0098, Imo0653, Imo0782. Imo0785, Imo1424, Imo1529, lmo2215, and $l m o 2596)$ encode membrane proteins [74], neither genes that encode for cell wall proteins nor genes that encode for secreted proteins or membrane proteins (based on the listings in LEGER) were significantly overrepresented among the 36 genes under positive selection (one-sided Fisher's exact test). One COG, "Signal transduction mechanisms", had a significant association with positive selection (nominal $P=0.008$; one-sided Fisher's exact test) though, suggesting an enrichment for genes under positive selection in this category. However, after correction for multiple comparisons, the association is not significant $(P=0.098$; Bonferroni correction). Because of the low number of genes under positive selection, it was not possible to assess the association between positive selection and most COGs. We thus assessed whether the distribution of the $p$-values for each test deviates from the random distribution for any of the COGs using a Utest. After Bonferroni correction, none of the COGs showed evidence for association with lower $p$-values (indicating evidence for positive selection) for either the lineage I (TLM1A) or the lineage II branch test (TLM2A). While three COGs (i.e., "Cell wall/membrane biogenesis", "Coenzyme transport and metabolism", and "Amino acid transport and metabolism") were associated with lower $p$-values for the TLI/LM test (see Fig. 3), only the association for the "Cell wall/membrane biogenesis" COG was significant after Bonferroni correction (nominal $P=0.004$; Bonferroni corrected $P=0.036$ ). Importantly, genes in this COG were not significantly associated with evidence for recombination, suggesting that a significant tendency for these genes to be under positive selection was not driven by an enrichment of genes with a history of recombination.

Among the 36 genes that showed evidence for positive selection, 29 genes also showed evidence for recombination, including five genes for which only one of the four recombination tests was significant. Statistical analyses showed that genes with evidence for recombination were overrepresented among the 36 genes found to be under positive selection (chi-square, $P<0.001$ ). Among the seven genes with evidence for positive selection and no evidence for recombination, five and two genes showed evidence for positive selection in the lineage II ancestral branch and the L. monocytogenes/L. innocua branch, respectively; none of these genes showed evidence for positive selection in the lineage I ancestral branch.

\section{Core genome genes encoding MHC antigen do not show evidence for positive selection}

The six core genome genes encoding antigens known to induce adaptive cellular immunity against $L$. monocytogenes in mice [75-82] were evaluated for evidence for positive selection. Epitopes in these antigens are presented to $\mathrm{CD}^{+}$or $\mathrm{CD} 4{ }^{+} \mathrm{T}$ cells through MHC class Ia, Ib or II molecules. One MHC antigen (a putative 23 aa leader peptide encoded by a transcription attenuator upstream of lmo2165) showed no nonsynonymous changes and was thus not formally tested for positive selection. The other five MHC antigens (p60, encoded by iap; LemA, 


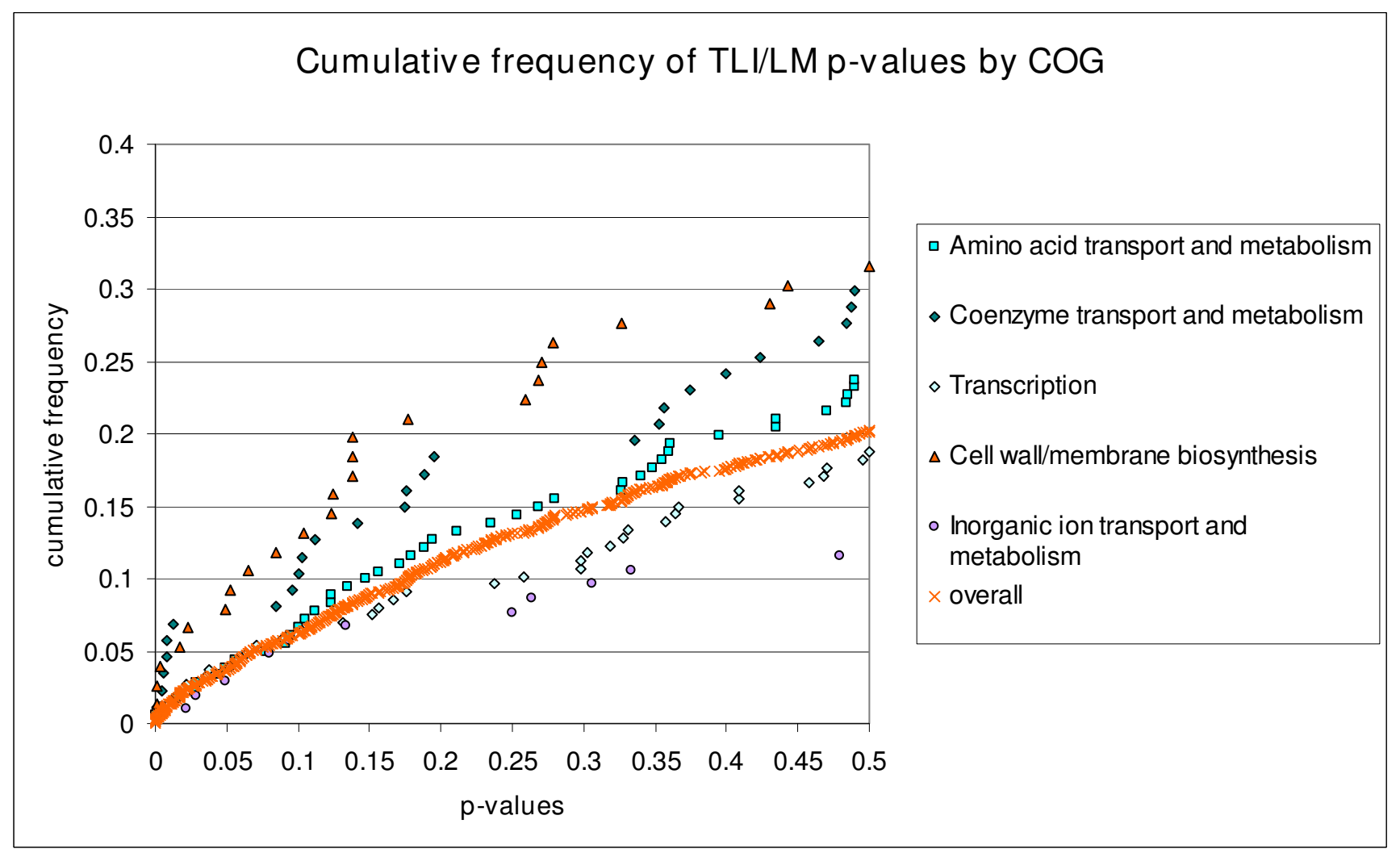

\section{Figure 3}

Cumulative distribution of the $p$-values obtained from TLI/LM for selected COGs. "Overall" represents all $p$-values regardless of the COG classification. Genes involved in "Cell-wall/membrane biosynthesis", "Coenzyme transport and metabolism", and "Amino acid transport and metabolism" showed a tendency to have lower p-values in comparison with all genes analyzed, while genes involved in "Transcription" and "Inorganic ion transport and metabolism" showed a tendency to have higher $p$-values than all genes analyzed.

encoded by lemA; a lipoprotein encoded by lmo1388; an extracellular solute-binding protein encoded by $1 m 00135$; and a protein with unknown function encoded by Imo1602) showed no evidence for positive selection. Moreover, the protein alignment of these five antigens showed no amino acid changes in the major epitope regions.

\section{Lineage II strains harbor more recombinant fragments than lineage I strains}

While the four recombination tests detailed above showed that a considerable number of genes in the $L$. monocytogenes/L. innocua core genome had evidence for recombination, these analyses did not allow for easy determination of the recipient strain and thus did not permit us to test the hypothesis that L. monocytogenes lineages differ in their frequency of gene fragment acquisition by recombination. ClonalFrame allows for identification of the recipient strains in recombination events and was thus used to analyze a set of 40 randomly selected genes $(c l p X$, lmo0343, Imo0405, pflC, phoP, lmo1436, Imo1460, Imo1537, hemC, сcpA, Imo1623, Imo1790, Imo2262, рерC, lmo2391, trxB, Imo0190, Imo0860, Imo0877, Imo1087, proA, Imo0992, smbA, Imo1401, Imo1420, opuCC, trpD, Imo1693, purK, Imo1825, panB, Imo0028, Imo2175, Imo2348, lmo2566, lmo0487, Imo0878, Imo1004, lmo1011, and $c b i H$ ) for evidence of recombination and to determine the recipient strains in the recombination events that were identified. Due to computational constraints, testing larger number of genes was not easily feasible. The 40 genes were randomly chosen from a set of 1227 genes that showed no evidence for positive selection, had at least 5 informative sites and had alignment lengths between 600 and 1400 nucleotides. Among the 40 genes selected, 20 showed evidence for recombination in the genome-wide analysis. As recipient lineages cannot be reliably determined for recombination events in the lineage I and II ancestral branches, we only analyzed recombination events in the external branches (Fig. 4). Eleven recombination events were identified in the two lineage II strains 
A)

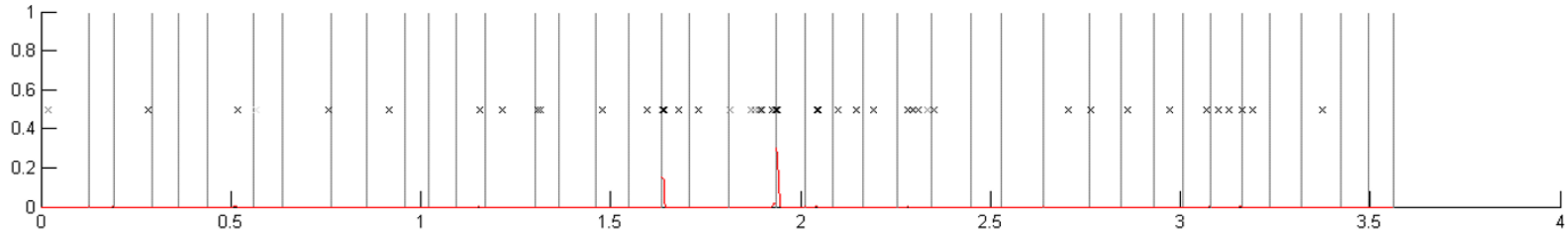

B)

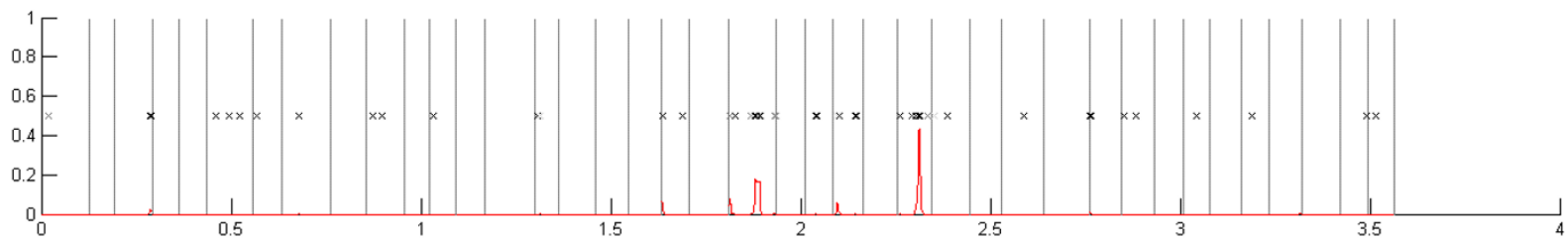

C)

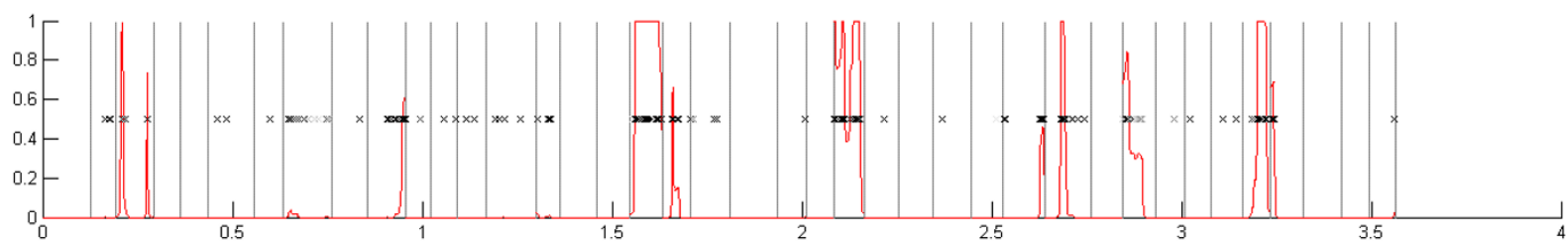

D)

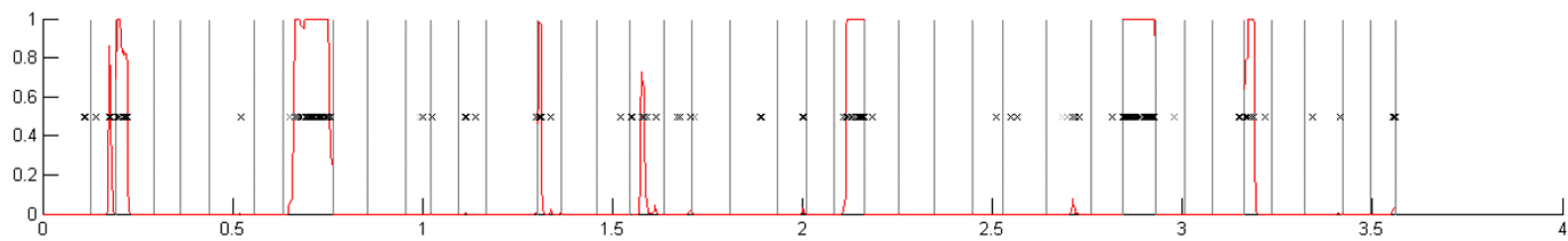

Figure 4

Recombination events identified by Clonal Frame, using the concatenated alignment of 40 randomly selected genes, in the external branches of the L. monocytogenes strains (A) H7858, (B) F2365, (C) F6854, and (D) EGDe. Each of the 40 genes is represented between gray vertical lines. The order of the genes (left to right) is as follow: $c l p X$ (Imo / 268), Imo0343, Imo0405, pflC (Imo / 407), phoP (Imo250I), Imo / 436, Imo / 460, Imo I 537, hemC (Imo I 556), ccpA (Imo I 599), Imo 1623, Imo I 790, Imo2262, pepC (Imo2338), Imo239I, trxB (Imo2478), Imo0 190, Imo0860, Imo0877, Imol 087, proA (Imo I 259), Imo0992, smbA (Imol 3 I3), Imo / 40I, Imo / 420, opuCC (Imo /426), trpD (Imo / 63 I), Imo I 693, purK (Imo I 774), Imo I 825, panB (Imo 1902), Imo0028, Imo2 I 75, Imo2348, Imo2566, Imo0487, Imo0878, Imo 1004, Imo I0I I, cbiH (Imol I99). "x" indicate substitutions inferred to have occurred in the respective branches. Red lines represent the probability for each nucleotide to have been imported by means of recombination. Values at the bottom represent the position in the alignment in kilobases.

(five in F6854 and six in EGD-e), while no recombination events were identified in the two lineage I strains (H7858 or F2365); in this data set, lineage I is thus significantly less likely to have recombination events as compared to lineage II $(P<0.001$; Fisher's exact test $)$.

\section{Analyses of five gene sequences obtained for $40 \mathrm{~L}$. monocytogenes isolates confirm positive selection and recombination patterns observed in the genome-wide analyses}

Five genes (Table 5) were selected for sequencing in a set of 40 L. monocytogenes isolates (representing lineage and source diversity; see Additional file 1) to confirm the positive selection and recombination patterns observed in the genome-wide analyses. The five genes chosen for these analyses included (i) cheA (lmo0692), which showed significant evidence for recombination (all tests significant) and positive selection with TLM1A; (ii) lmo0693, which showed evidence for positive selection with TLM2A and had no evidence for recombination; (iii) flaR (lmo1412), which showed evidence for positive selection with TLM2A and no evidence for recombination; (iv) lmo2537, which showed significant evidence for recombination with Maximum $\chi^{2}$ but no evidence for positive selection; and (v) phoP (lmo2501), which showed evidence for recombination with GENECONV but showed no evidence for positive selection. Positive selection and recombination analyses were performed with gene alignments containing 
Table 5: Positive selection and recombination analyses of 5 genes in $\mathbf{4 5}$ isolates( ${ }^{(1)}$

\begin{tabular}{|c|c|c|c|c|c|c|}
\hline Gene & Function & $\begin{array}{c}\text { Recombination } \\
\text { evidence }^{(2)}(p \text {-value })\end{array}$ & $\begin{array}{c}\text { Positive selection } \\
\text { evidence }^{(3)}(p \text {-value })\end{array}$ & $\omega^{(4)}$ & $p^{(5)}$ & BEB $^{(6)}$ sites (probability) \\
\hline cheA & $\begin{array}{l}\text { Two-component sensor } \\
\text { histidine kinase CheA, } \\
\text { involved in chemotaxis } \\
\text { (Dons et al., 2004) }\end{array}$ & $\begin{array}{c}\text { GENECONV }(<0.00 \mathrm{I}), \mathrm{NSS} \\
(<0.00 \mathrm{I}), \operatorname{Max} \chi^{2}(<0.00 \mathrm{I}) \\
\mathrm{PHI}(<0.00 \mathrm{I})\end{array}$ & LIIIA/C-LI $(<0.001)$ & $\infty$ & 0.002 & 140 (98\%); \\
\hline $\operatorname{Imo0693}$ & $\begin{array}{l}\text { Putative flagellar motor } \\
\text { switch protein, involved in } \\
\text { motility }\end{array}$ & NSS (0.033) & LII $(<0.00$ I $)$ & $\infty$ & 0.022 & $\begin{array}{l}17(73 \%) \\
18(98 \%)\end{array}$ \\
\hline flaR & $\begin{array}{l}\text { Histone like-DNA topology } \\
\text { modulator, involved in } \\
\text { regulation of flagellin } \\
\text { expression (Sanchez- } \\
\text { Campillo et al., 1995) }\end{array}$ & $\begin{array}{c}\text { GENECONV }(0.010), \text { Max } \\
\chi^{2}(0.010), \mathrm{PHI}(0.005)\end{array}$ & LII (0.002) & 14.1 & 0.046 & $\begin{array}{l}4(90 \%) \\
12(99 \%) \\
68(80 \%)\end{array}$ \\
\hline phoP & $\begin{array}{l}\text { Putative two-component } \\
\text { response phosphate } \\
\text { regulator PhoP }\end{array}$ & $\begin{array}{c}\text { GENECONV }(0.014), \text { NSS } \\
(0.001), \operatorname{Max} \chi^{2}(0.020), \mathrm{PHI} \\
(0.003)\end{array}$ & - & - & - & - \\
\hline $\operatorname{Imo2537}$ & $\begin{array}{l}\text { Putative UDP-N- } \\
\text { acetylglucosamine-2- } \\
\text { epimerase, involved in } \\
\text { teichoic acid biogenesis } \\
\text { (Dubail et al., 2006) }\end{array}$ & $\begin{array}{c}\text { GENECONV }(<0.00 \mathrm{I}), \mathrm{NSS} \\
(<0.00 \mathrm{I}), \operatorname{Max} \chi^{2}(<0.00 \mathrm{I}) \\
\mathrm{PHI}(<0.00 \mathrm{I})\end{array}$ & - & - & - & - \\
\hline
\end{tabular}

\footnotetext{
(1) Analyses were performed using an alignment of these 5 genes for the $40 \mathrm{~L}$. monocytogenes isolates, for which these genes were sequenced here (see Supp. Table I), as well as the four $L$. monocytogenes and one $L$. innocua strain for which full genome sequences were available (Table I). (2) NSS: Neighbour Similarity Score; Max $\chi^{2}$ : Maximum $\chi^{2}$; PHI: Pairwise Homoplasy Index; GENECONV performed with g-scale = I did not show significant inner fragments for any of the five genes, however four genes showed significant inner fragments in GENECONV performed with g-scale $=2$, these $p$-values are reported here. The g-scale setting in GENECONV is associated with the number of polymorphisms allowed in a putative recombinant fragment; more polymorphisms are allowed as the g-scale value decreases from 3 to I,

(3) Branches where positive selection was identified. LIIIA/C-LI: ancestral branch of lineages IIIA/C and I isolates (branch B in Figure 5); LII: Ancestral branch of lineage II isolates (branch $\mathrm{F}$ in Figure 5); there was no evidence for positive selection in phoP and Imo2537.

(4) $\omega=d_{N} / d_{S}$ (number of nonsynonymous changes per nonsynonymous sites/Number of synonymous changes per synonymous sites); infinite values of $\omega(\infty)$ indicate that the model did not find synonymous changes for the branches tested $\left(d_{S}=0 ; \omega \sim \infty\right)$.

(5) Proportion of sites under positive selection.

(6) this column lists sites identified using Bayes Empirical Bayes (BEB) as being under positive selection; numbers identify the amino acid sites (in alignments) that are under positive selection; "probabilities" refer to the posterior probabilities that the respective sites evolved by positive selection.
}

45 sequences ( 40 gene sequences determined here as well as the respective gene sequences from the four L. monocytogenes and the one L. innocua genome [Table 1]).

Three genes (lmo2537, phoP, and cheA) showed significant evidence for recombination with all four recombination analyses (i.e., GENECONV, NSS, Maximum $\chi^{2}$, and PHI), consistent with the genome-wide analyses, which also found evidence for recombination in these genes. While flaR showed no evidence for recombination in the genome-wide analyses, analyses of the $45 \mathrm{flaR}$ sequences showed significant evidence for recombination with Maximum $\chi^{2}$, PHI, and GENECONV (Table 5); these findings suggest that at least some of the additional flaR sequences represent recombinant alleles. Based on the 45 sequences, Imo0693 showed marginally significant evidence for recombination with NSS $(\mathrm{P}=0.033)$ and no evidence for recombination with the other three methods, largely consistent with the genome-wide recombination analyses, which found no evidence for recombination in this gene.
ClonalFrame analysis on a concatenated alignment of the five genes (for all 45 isolates) identified 7, 2, 2, and 3 recombination events in the external branches for cheA, phoP, flaR, and $l m o 2537$. No recombination events were identified in external branches for lmo0693. The recombination events identified in branches other than the ancestral branches leading to a given lineage involved 1, 7, 3, and 3 lineage I, II, IIIA/C, and IIIB branches as recipients in recombination events, respectively. Lineage II strains were significantly more likely to be involved as recipients in recombination events as compared to lineage I strains $(P=0.013$, Fisher's exact test $)$. ClonalFrame also allowed us to estimate the relative rate of recombination over mutation for these five genes. While, on average, mutations are 4.5 times more common than recombination events (95\% IC $=\{3.0 ; 7.3\})$, a recombination event is 1.9 times more likely to change a single nucleotide than a point mutation $(95 \% \mathrm{IC}=\{1.27 ; 2.6\})$.

Analyses of positive selection on the 45 sequences for the five genes yielded results similar to those obtained in the genome-wide analyses. As in the genome-wide analyses, 
we found no evidence for positive selection in the 45 sequences for $1 \mathrm{mo} 2537$ and phoP. For $1 \mathrm{mo0} 093$ and flaR, the lineage II ancestral branch was identified as evolving by positive selection $(P<0.001$ and $P=0.002$, respectively; the same branches were identified as being under positive selection in the genome-wide analyses). In Imo0693, two adjacent aa sites (17 and 18) were identified as being under positive selection, including one site identified with a posterior probability $>95 \%$ (Table 5 ). In flaR, three amino acid sites were identified as evolving by positive selection in the lineage II ancestral branch, including one site identified with a posterior probability $>95 \%$ (Table 5). While the genome-wide analysis for cheA found evidence for positive selection in the lineage I ancestral branch, analysis of the 45 sequences did not find evidence for positive selection in this branch $(P=0.207)$, but found significant evidence $(P<0.001)$ for positive selection in the ancestral branch that leads to lineages I and IIIA/C isolates (branch B, Fig. 5), a branch that was not present in the tree used in the genome-wide analyses (due to the absence of lineage IIIA/C strains in that data set). A single amino acid site was identified as evolving by positive selection in cheA (posterior probability > 95\%; Table 5); isolates in lineage I and IIIA/C have glutamine at this site, while all other isolates, including L. innocua CLIP11262, bear an alanine. This amino acid site lies within the P2 domain of the CheA protein, which is the binding site for the response regulator, CheY; cheY itself seems to be extremely conserved (with no nonsynonymous change among the five strains included in the genome-wide analyses).

Interestingly, all three aa sites identified in flaR, lmo0693, and $c h e A$ as being under positive selection with posterior probabilities $>95 \%$, involved nucleotide substitutions at all three codon positions (e.g., cheA aa site 140 GCC $\rightarrow$ CAG). These findings suggest that these codons evolved rapidly in the branches under positive selection. The nucleotide diversity in synonymous sites ranged from 0.141 to 0.151 among the three genes with evidence for positive selection while the nucleotide diversity in the synonymous sites of $1 m o 2537$ and $p h o P$, which showed no significant evidence for positive selection, were 0.338 and 0.449 , respectively. This suggests that significant tests for positive selection were not due to higher rates of synonymous substitutions, which could result in an underestimation of the number of synonymous changes due to recurrent mutations in synonymous sites.

\section{Unrelated L. monocytogenes isolates carry independently acquired premature stop codons in flaR}

Among the $45 \mathrm{~L}$. monocytogenes flaR sequences, we identified six sequences with distinct premature stop codons in flaR (Fig. 5), including five caused by frameshift mutations and one due to a nonsense mutation. The mutations leading to the premature stop codon were found in different regions of the sequence (Additional file 3 ). While one of these frameshift mutations was found in two isolates (FSL S4-766 and FSL N4-015, two closely related lineage II strains [Fig. 5]), all other mutations were only identified in one isolate each. flaR premature stop codons were found in different $L$. monocytogenes lineages, including lineage I (one frameshift and the nonsense mutation), lineage II (three different frameshift mutations), and lineage IIIB (one frameshift mutation) isolates. The isolates carrying premature stop codons in flaR were from human clinical cases $(\mathrm{n}=4)$, animals $(\mathrm{n}=2)$ and natural environment $(\mathrm{n}=1)$. No statistical association could be identified between the presence of premature stop codon and source of the isolate (Fisher's exact test).

Since flaR has been previously shown to be involved in $L$. monocytogenes motility [83], swarming experiments were conducted to assess the swarming ability of six isolates presenting each of the six different mutations leading to premature stop codons, three isolates bearing full length flaR and an isogenic flaR null mutant. Isolates harboring naturally occurring premature stop codons in flaR showed, on average, significantly reduced swarming areas $(P<0.001$; One-sided U-Test $)$ and FSL F2-649, which harbor a premature stop codon in flaR due to a nonsense mutation, had the smallest swarming area among all natural isolates $(P<0.001$; One-sided U-Test). Even though all isolates with flaR premature stop codons still showed some swarming and the 10403S $\Delta$ flaR showed no significant reduction in swarming ability, these findings suggest that the frameshift mutations in flaR may affect motility, at least in some strains.

\section{Discussion}

We have chosen two closely related species within the genus Listeria, i.e., the pathogen $L$. monocytogenes and the non-pathogenic $L$. innocua, as a model system to further probe the evolution of bacterial pathogens using a comparative genomics approach. While comparative genomics approaches have provided important data on the importance of gene acquisitions in the evolution of bacterial pathogens in general $[2,84,85]$ and in the evolution of L. monocytogenes in particular (e.g., by identifying a number of virulence genes associated with pathogenic Listeria spp.), our understanding of the contributions of recombination and positive selection to the evolution of the L. monocytogenes/L. innocua core genome has been limited so far.

\section{Recombination and positive selection both contribute to evolution of $L$. monocytogenes, but the relative}




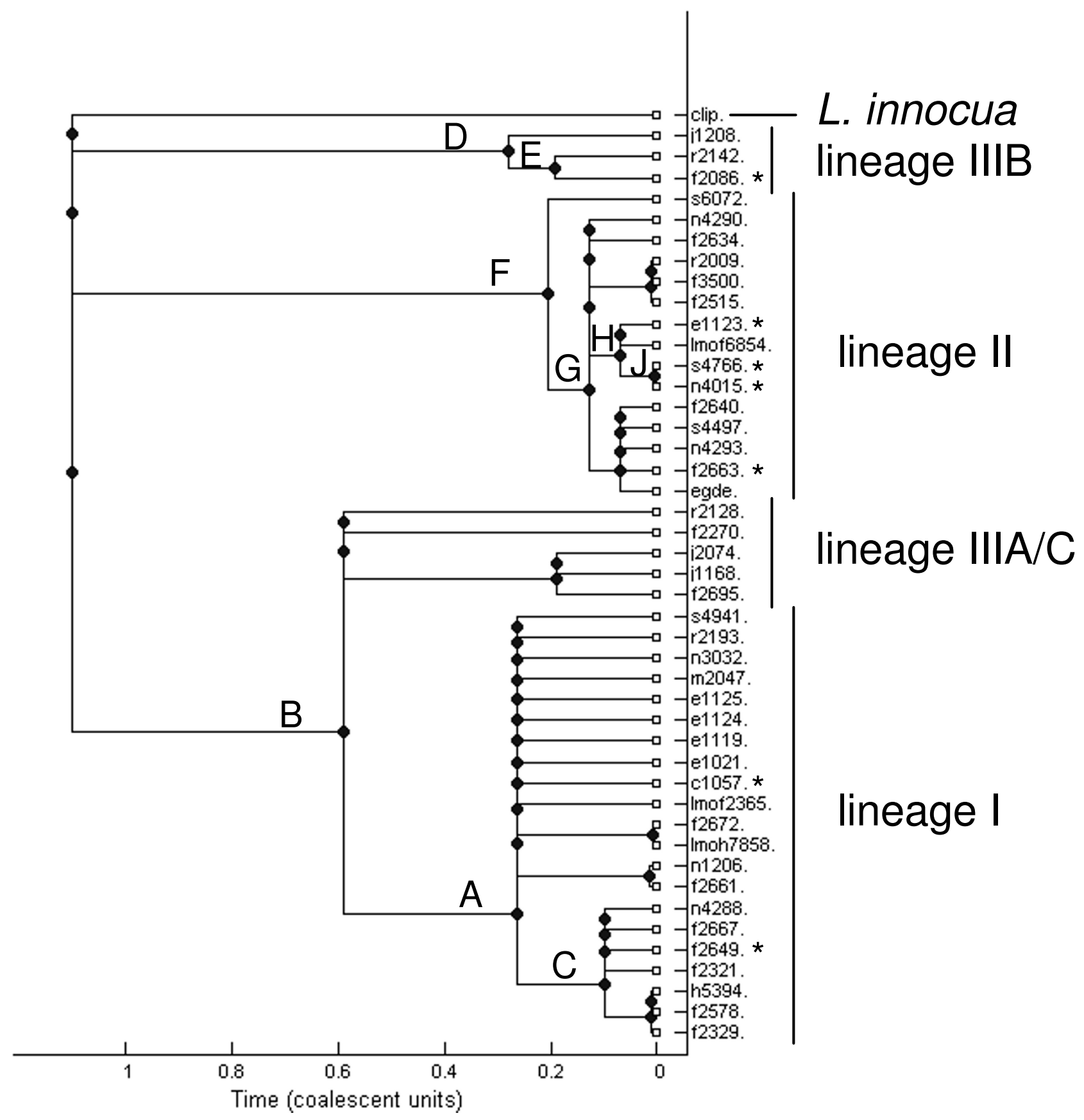

Figure 5

Phylogenetic consensus tree generated by ClonalFrame from the concatenated alignment of cheA, flaR, Imo0693, phoP and Imo2537 for 45 isolates. The $95 \%$ consensus phylogeny was obtained from two independent runs of ClonalFrame. This phylogeny clearly shows that the $L$. monocytogenes isolates form four distinct clusters, with lineage IIIA and IIIC (IIIA/C) isolates forming a sister group to lineage I isolates, while lineage IIIB isolates form an independent cluster that diverged earlier from the other isolates. Internal branches that showed evidence for recombination are labeled from $A$ to $\mathrm{J}$. Isolates with premature stop codons in flaR are marked with*. 


\section{contribution of these evolutionary forces differs among $\mathbf{L}$.} monocytogenes lineages

Overall, almost half of the genes present in L. monocytogenes/L. innocua core genome showed evidence for intragenic recombination (location of these genes is shown in Fig. 2). Only a much smaller proportion of the genes in the core genome $(1.7 \%)$ showed evidence for positive selection. By comparison, a recent genomic study on the genus Streptococcus reported evidence for recombination in 18 to $37 \%$ of the genes in the core genome and evidence for positive selection in 11 to $34 \%$ of the genes in the core genome. This study was able to use a larger number of genome sequences (i.e., 26 genomes) and used different criteria for selection of genes with significant evidence for positive selection and recombination (i.e. only genes significant by all three tests for recombination were considered as recombinants) though [2]. While a comparison of the frequency of genes with evidence of recombination between Listeria and Helicobacter pylori, which appears to be panmictic [17], will be of interest, no genome wide studies of recombination in Helicobacter have been reported to date. In both gene-specific and multilocus sequence typing (MLST) studies, evidence has previously been found for contributions of recombination to the evolution of different L. monocytogenes genes, even though many of the genes identified as having an apparent history of recombination appear to be lineage and species specific, including a number of genes in the internalin family [4,9] and the prfA virulence gene cluster [12]. While some studies also have identified housekeeping genes with significant evidence for recombination [12], the magnitude of recombination in Listeria on a genomewide level has not previously been known. Interestingly, it seems that although homologous recombination between closely related strains of $L$. monocytogenes is common, non-homologous recombination seems to be rare given the high synteny of the different Listeria genomes [[51], this study] and the relatively small number of strain and lineage specific genes (e.g., [83] and [51] genes specific to serotype $1 / 2 \mathrm{a}$ and $4 \mathrm{~b}$ strains, respectively [51]). While others have also previously observed positive selection in L. monocytogenes, all previously identified genes under positive selection were virulence genes (i.e., actA, inlA, inlB, inlC, inlC2 and inlF) $[4,9,12]$, which were specific to L. monocytogenes or selected $L$. monocytogenes lineages. We are thus the first to identify genes in the core genome which are under positive selection, indicating that positive selection does not just act on accessory and virulence genes.

Overall, most genes in the core genome found to be under positive selection also showed evidence for recombination; an association of recombination and positive selection was also previously observed in a genome-wide study on the evolution of genes in the genus Streptococcus [2].
Occurrence of both positive selection and recombination in specific genes has also previously been reported for selected $L$. monocytogenes virulence genes [4,9] as well as in other microorganisms $[1,2,10,11,16]$.

While it has been shown that high recombination rates can lead to false positives in overall analysis using PAML, such as the TO test [86], no studies have evaluated the effect of recombination on the branch-site tests and it is unclear how recombination affects this analysis. The fact that, in our analyses, more than 1000 genes showed evidence for recombination but no evidence for positive selection suggests that the positively selected genes identified harbor distinct features that allowed their identification. As previously pointed out $[2,9]$, some horizontally transferred fragments may also be more likely to be under positive selection, and positive selection may be important for fixation of recombinant gene and/or for adaptation of the newly acquired genes or alleles to a different function.

In analyses of sequence data for 40 genes, lineage II strains were significantly more likely to be identified as recipients of DNA fragments by horizontal gene transfer, indicating either more frequent lateral gene transfer or more frequent fixation of recombinant fragments. Higher frequency of recombinant fragments among lineage II strains has also previously been described for L. monocytogenes specific virulence genes (e.g., internalin genes $[4,9])$ and for some housekeeping genes [87]. The genetic basis of the promiscuity of lineage II isolates is currently unknown but it might be related to the observation that lineage II isolates appear to be overrepresented in foods, farms and natural environments [41], where Listeria bacteriophages (listeriophages) may be common due to the frequent presence of $L$. monocytogenes in some of these environments [88,89]. While listeriophages can perform generalized transduction [90], transduction between isolates of serotypes $1 / 2 \mathrm{a}$ and $4 \mathrm{~b}$ has not been shown. Most listeriophages appear to be serotype-specific and phage host-specificity could account for the differences in recombination frequency between lineages. Alternatively, lineage I strains might have a more effective restriction systems for degradation of foreign DNA, a more efficient mismatch repair system that avoids incorporation of foreign DNA fragments into the chromosome, or may show reduced competency.

Our genome-wide analyses also indicated that positive selection occurred in more genes in the ancestral branch of lineage II as compared to the ancestral branch of lineage I. Interestingly, one gene with evidence for positive selection in the ancestral branch of lineage II encodes a putative transcriptional antiterminator of the BglG family (lmo0297). As another antiterminator of the BglG family 
(BvrA), which is only present in lineage II isolates [50], has been shown to be involved in cellobiose-dependent repression of PrfA-dependent virulence genes in L. monocytogenes [91], Imo0297 may have evolved to facilitate specific transcriptional repression functions in lineage II. Positive selection in the lineage II ancestral branch was further confirmed for two genes (flaR, lmo0693) in a larger isolate set. As lineage II strains are found in many different environments, including natural environment, farms, foods, animals with clinical disease, as well as human clinical cases (although less frequently than lineage I isolates) [41], one could hypothesize that lineage II isolates are exposed to a more diverse repertoire of distinct selective pressures than lineage I strains, which appear to be less common in natural environments and foods and seem to be more likely to be adapted to human or mammalian hosts $[41,42]$.

\section{Diversification, by multiple mechanisms, of cell wallI membrane biogenesis and motility-related genes may play a particularly important role in the evolution of $L$. monocytogenes}

In our study, genes involved in cell wall/membrane biogenesis showed a significant tendency to be identified as being under positive selection in the L. monocytogenes/L. innocua branch, suggesting that positive selection in these genes contributed to the divergence of these two species. L. monocytogenes genes encoding proteins involved in cell wall metabolism and encoding cell wall-anchored proteins have also previously been identified as harboring more nonsynonymous changes than genes involved in other functions [51], further supporting an important role for diversification of these gene categories in the evolution of L. monocytogenes. Specific surface associated proteins identified as being under positive selection included genes involved in transport of carbohydrates such as $m p t D$, which appears to be involved in resistance to class IIa bacteriocins $[92,93]$. Class IIa bacteriocins are antimicrobial peptides frequently produced by lactic acid bacteria in foods [93], and resistance to these compounds are likely to confer an advantage to L. monocytogenes isolates in foods and environments. In addition, a putative glycosyl transferase (lmo2121) was identified as having evolved by positive selection in lineage I; glycosyl transferases could be associated with the differences in the somatic antigens in different serotypes and might be associated with strain differences in virulence and immunogenicity [51,94-96]. Functionally, active and rapid evolution of genes involved in cell wall/membrane biogenesis is likely to be important to allow bacteria to adapt to different and possibly rapidly changing environments, including, but not limited to, competing microorganisms as well as innate and adaptive immune system effectors in different host species. Our findings are consistent with a recent genome-wide study, which showed that most $E$. coli pro- teins that undergo positive selection are exposed on the cell surface, including a number of proteins known to interact with bacterial, host, or phage surface molecules [8].

A number of genes involved in flagellar synthesis and motility (e. g., flaR, lmo0693 and cheA) also showed evidence for positive selection, including when these genes were analyzed in a larger set of more diverse isolates. Imo0693, cheA and several other genes involved in motility and chemotaxis have also been found to be expressed more highly in four lineage I strains as compared to two lineage II strains [97], further suggesting a difference in regulation of motility and chemotaxis functions between the two lineages. Motility and flagellar expression appear to contribute to both biofilm formation [98] and host cells invasion $[68,99,100]$ in $L$. monocytogenes, and diversification in these genes is likely to be important for adaptation to different host or non-host environments. Interestingly, seven isolates showed premature stop codons in flaR, including six due to frameshift mutations and one due to a nonsense mutation. While FlaR has been reported to be a histone-like protein that regulates transcription of the flagellin gene flaA in L. monocytogenes serotype $1 / 2 \mathrm{c}$ lineage II strain LO28 (as determined in a transposon mutant; [83]), a non-polar flaR null mutant in a serotype 1/2a lineage II strain (generated in our study reported here) did not show reduced motility at room temperature, even though the LO28 flaR mutant was reported to be non-motile at this temperature [83]. As shown here, natural isolates with premature stop codons in flaR showed, though, on average, significant reduced ability to swarm as compared to isolates harboring a fulllength gene. flaR thus seems to have strain or perhaps serotype or lineage specific functions in L. monocytogenes and flaR inactivation in some strains is likely to be recent since most frameshift/nonsense mutations are isolate and not clade-specific. Alternatively, some or all frameshift and nonsense mutations could be reversible and flaR might be phase-variable, a tempting hypothesis as phasevariable flagella-related genes have been described in a number of other bacteria [101-104]. Interestingly, previous studies have shown that inlA, which encodes another L. monocytogenes surface protein that promotes mammalian host cell invasion, also carries several different premature stop codons in both lineage I and II strains $[9,46,105-$ 108]. The isolates with truncated InlA seem to be more common in foods [46] and show significantly reduced invasiveness for human intestinal epithelial cells [46], suggesting reduced virulence of these strains. Diversification by both positive selection and gene inactivation of genes encoding surface molecules with a role in virulence thus appears to be broadly important in the adaptation of L. monocytogenes to host and non-host associated environments. 


\section{Conclusion}

Our analyses reported here indicate that both recombination and positive selection contribute to the evolution of the L. monocytogenes/L. innocua core genome. While considerably more genes appear to be affected by recombination, positive selection still appears to play an important role in the evolution of both genes in the core genome (this study) as well as L. monocytogenes virulence genes that are not part of the core genome $[4,9,12]$. The list of genes identified as being under positive selection hopefully can be used by the scientific community to advance the discovery of genetic factors that allow this organism to adapt to diverse environments and hosts. In particular, our data suggest important roles for positive selection and diversification of genes encoding proteins associated with the cell wall and membrane biosynthesis on the evolution of L. monocytogenes.

Overall, genes in lineage I isolates were less likely to be affected by either recombination or positive selection, possibly reflecting that this lineage has experienced a recent bottleneck, as previously proposed [87]. Frequent recombination in combination with positive selection of some genes in lineage II strains, on the other hand, may be important for the evolution of this generalist lineage, which is present in many different environments and host, including human clinical cases (although less common than lineage I). In combination with previous studies that have shown considerable differences in frequency of recombination and positive selection among different Streptococcus lineages and species [2], our findings further show that even closely related bacterial lineages may differ in mechanisms contributing to their evolution.

\section{Abbreviations}

COG: Clusters of Orthologous Groups of proteins; LRT: Likelihood Ratio Test; TO: Test Overall; an overall test for positive selection was carried out using the null model M1a (Nearly-neutral) and the alternative model M2a in PAML; TLM1A: Test $\underline{L}$. monocytogenes lineage I Ancestral; this describes the branch-site test 2 used to test for evidence of positive selection in the ancestral branch of $L$. monocytogenes lineage I.; TLM2A: Test $\underline{L}$. monocytogenes lineage II Ancestral; this describes the branch-site test 2 used to test for evidence of positive selection in the ancestral branch of $L$. monocytogenes lineage II; TLI/LM: Test $\underline{L}$. innocua/L. monocytogenes; this describes the branch-site test2 used to test for evidence of positive selection in the branch separating L. monocytogenes and L. innocua.

\section{Authors' contributions}

RHO outlined, performed, and interpreted the phylogenetic and statistical analyses, and drafted the manuscript. QS performed orthologous gene clustering and alignment, and implemented the analysis on the parallel com- puter cluster. MW supervised the project, participated in the design of the study and data interpretation, and finalized the manuscript. All authors read and approved the final manuscript.

\section{Additional material}

\section{Additional file 1}

Isolates used to confirm positive selection and recombination patterns in five selected genes.

Click here for file

[http://www.biomedcentral.com/content/supplementary/1471-

2148-8-233-S1.doc]

\section{Additional file 2}

Primers used for re-sequencing.

Click here for file

[http://www.biomedcentral.com/content/supplementary/1471-

2148-8-233-S2.doc]

\section{Additional file 3}

Alignment of the flaR sequence for seven isolates with premature stop codons.

Click here for file

[http://www.biomedcentral.com/content/supplementary/14712148-8-233-S3.doc]

\section{Acknowledgements}

This work was partially supported by USDA Special Research Grant 200534459-15625 (to MW); the computer cluster used in the data analysis is partially funded by Microsoft. We thank Alphina Ho and Jasmine Badamo for help with PCR amplification and sequencing of some of the genes.

\section{References}

I. Urwin R, Holmes EC, Fox AJ, Derrick JP, Maiden MC: Phylogenetic evidence for frequent positive selection and recombination in the meningococcal surface antigen PorB. Mol Biol Evol 2002, 19:1686-1694.

2. Lefebure T, Stanhope MJ: Evolution of the core and pan-genome of Streptococcus: positive selection, recombination, and genome composition. Genome Biol 2007, 8:R7I.

3. Charlesworth J, Eyre-Walker A: The rate of adaptive evolution in enteric bacteria. Mol Biol Evol 2006, 23:1348-1356.

4. Tsai YH, Orsi RH, Nightingale KK, Wiedmann M: Listeria monocytogenes internalins are highly diverse and evolved by recombination and positive selection. Infect Genet Evol 2006, 6:378-389.

5. Perfeito L, Fernandes L, Mota C, Gordo I: Adaptive mutations in bacteria: high rate and small effects. Science 2007, 3 I 7:8I3-8I5.

6. Chen SL, Hung CS, Xu J, Reigstad CS, Magrini V, Sabo A, Blasiar D, Bieri T, Meyer RR, Ozersky P, Armstrong JR, Fulton RS, Latreille JP, Spieth J, Hooton TM, Mardis ER, Hultgren SJ, Gordon JI: Identification of genes subject to positive selection in uropathogenic strains of Escherichia coli: a comparative genomics approach. Proc Natl Acad Sci USA 2006, 103:5977-5982.

7. Inagaki $Y$, Susko E, Roger AJ: Recombination between elongation factor I alpha genes from distantly related archaeal lineages. Proc Natl Acad Sci USA 2006, 103:4528-4533.

8. Petersen L, Bollback JP, Dimmic M, Hubisz M, Nielsen R: Genes under positive selection in Escherichia coli. Genome Res 2007, 17:1336-1343.

9. Orsi RH, Ripoll DR, Yeung M, Nightingale KK, Wiedmann M: Recombination and positive selection contribute to evolution of Listeria monocytogenes inIA. Microbiology 2007, I53:2666-2678. 
10. Peek AS, Souza V, Eguiarte LE, Gaut BS: The interaction of protein structure, selection, and recombination on the evolution of the type-I fimbrial major subunit (fimA) from Escherichia coli. J Mol Evol 200I, 52:193-204.

II. Andrews TD, Gojobori T: Strong positive selection and recombination drive the antigenic variation of the PilE protein of the human pathogen Neisseria meningitidis. Genetics 2004, 166:25-32.

12. Nightingale KK, Windham K, Wiedmann M: Evolution and molecular phylogeny of Listeria monocytogenes isolated from human and animal listeriosis cases and foods. J Bacteriol 2005, | 87:5537-555।.

13. Cooper TF, Rozen DE, Lenski RE: Parallel changes in gene expression after 20,000 generations of evolution in Escherichia coli. Proc Natl Acad Sci USA 2003, 100:1072-1077.

14. Crozat E, Philippe N, Lenski RE, Geiselmann J, Schneider D: Longterm experimental evolution in Escherichia coli. XII. DNA topology as a key target of selection. Genetics 2005, 169:523-532.

15. McGraw EA, Li J, Selander RK, Whittam TS: Molecular evolution and mosaic structure of alpha, beta, and gamma intimins of pathogenic Escherichia coli. Mol Biol Evol 1999, 16:12-22.

16. Polley SD, Conway DJ: Strong diversifying selection on domains of the Plasmodium falciparum apical membrane antigen I gene. Genetics 200I, 158:1505-1512.

17. Suerbaum S, Smith JM, Bapumia K, Morelli G, Smith NH, Kunstmann E, Dyrek I, Achtman M: Free recombination within Helicobacter pylori. Proc Natl Acad Sci USA 1998, 95: I2619-12624.

18. Dykhuizen DE, Polin DS, Dunn JJ, Wilske B, Preac-Mursic V, Dattwyler RJ, Luft BJ: Borrelia burgdorferi is clonal: implications for taxonomy and vaccine development. Proc Natl Acad Sci USA 1993, 90:10163-10167.

19. Hill WG, Robertson A: The effect of linkage on limits to artificial selection. Genet Res 1966, 8:269-294.

20. Gerrish PJ, Lenski RE: The fate of competing beneficial mutations in an asexual population. Genetica 1998, 102-103(16): $127-\mid 44$.

21. Wilke CO: The speed of adaptation in large asexual populations. Genetics 2004, 167:2045-2053.

22. de Visser JAGM, Zeyl CW, Gerrish PJ, Blanchard JL, Lenski RE: Diminishing returns from mutation supply rate in asexual populations. Science 1999, 283:404-406.

23. Cooper TF: Recombination speeds adaptation by reducing competition between beneficial mutations in populations of Escherichia coli. PLOS Biol 2007, 5:e225.

24. Hadany L, Feldman MW: Evolutionary traction: the cost of adaptation and the evolution of sex. J Evol Biol 2005, I 8:309-3 I4.

25. Rice WR, Chippindale AK: Sexual recombination and the power of natural selection. Science 200I, 294:555-559.

26. Keightley PD, Otto SP: Interference among deleterious mutations favours sex and recombination in finite populations. Nature 2006, 443:89-92.

27. Johnson T, Barton $\mathrm{NH}$ : The effect of deleterious alleles on adaptation in asexual populations. Genetics 2002, 162:395-4II

28. Schmid MW, Ng EY, Lampidis R, Emmerth M, Walcher M, Kreft J, Goebel W, Wagner M, Schleifer KH: Evolutionary history of the genus Listeria and its virulence genes. Syst Appl Microbiol 2005, 28: $1-18$.

29. Mead PS, Slutsker L, Dietz V, McCaig LF, Bresee JS, Shapiro C, Griffin PM, Tauxe RV: Food-related illness and death in the United States. Emerg Infect Dis 1999, 5:607-625.

30. Edelson BT, Unanue ER: Immunity to Listeria infection. Curr Opin Immunol 2000, I 2:425-43I.

31. Ochsenbein AF, Fehr T, Lutz C, Suter M, Brombacher F, Hengartner $\mathrm{H}$, Zinkernagel RM: Control of early viral and bacterial distribution and disease by natural antibodies. Science 1999, 286:2156-2159.

32. Edelson BT, Cossart $P$, Unanue ER: Cutting edge: paradigm revisited: antibody provides resistance to Listeria infection. Immunol 1999, 163:4087-4090.

33. Walker SJ, Archer P, Banks JG: Growth of Listeria monocytogenes at refrigeration temperatures. J Appl Bacteriol 1990, 68:157-162.

34. Gray ML, Killinger AH: Listeria monocytogenes and listeric infections. Bacteriol Rev 1966, 30:309-382.
35. Phan-Thanh L: Physiological and biochemical aspects of the acid survival of Listeria monocytogenes. J Gen Appl Microbiol 1998 , 44:|83-19|.

36. Petran RL, Zottola EA: A study of factors affecting growth and recovery of Listeria monocytogenes Scott A. J Food Science 1989, 54:458-460

37. Sleator RD, Gahan CGM, O'Driscoll B, Hill C: Analysis of the role of betL in contributing to the growth and survival of Listeria monocytogenes LO28. Int J Food Microbiol 2000, 60:26I-268.

38. Roberts A, Nightingale K, Jeffers G, Fortes E, Kongo JM, Wiedmann M: Genetic and Phenotypic Characterization of Listeria monocytogenes lineage III. Microbiology 2006, 152:685-693.

39. McLauchlin J, Mitchell RT, Smerdon WJ, Jewell K: Listeria monocytogenes and listeriosis: a review of hazard characterisation for use in microbiological risk assessment of foods. Int J Food Microbiol 2004, 92: 15-33.

40. Jeffers GT, Bruce JL, McDonough PL, Scarlett J, Boor KJ, Wiedmann M: Comparative genetic characterization of Listeria monocytogenes isolates from human and animal listeriosis cases. Microbiology 200I, 147:1095-II04.

4I. Sauders BD, Durak MZ, Fortes E, Windham K, Schukken Y, Lembo AJ Jr, Akey B, Nightingale KK, Wiedmann M: Molecular characterization of Listeria monocytogenes from natural and urban environments. J Food Prot 2006, 69:93-105.

42. Gray MJ, Zadoks RN, Fortes ED, Dogan B, Cai S, Chen Y, Scott VN, Gombas DE, Boor KJ, Wiedmann M: Listeria monocytogenes isolates from foods and humans form distinct but overlapping populations. Appl Environ Microbiol 2004, 70:5833-584I.

43. Chen Y, Ross WH, Gray MJ, Wiedmann M, Whiting RC, Scott VN: Attributing risk to Listeria monocytogenes subgroups: dose response in relation to genetic lineages. I Food Prot 2006, 69:335-344.

44. Norton DM, Scarlett JM, Horton K, Sue D, Thimothe J, Boor KJ, Wiedmann M: Characterization and pathogenic potential of Listeria monocytogenes isolates from the smoked fish industry. Appl Environ Microbiol 200I, 67:646-653.

45. Wiedmann M, Arvik T, Bruce JL, Neubauer J, del Piero F, Smith MC Hurley J, Mohammed HO, Batt CA: Investigation of a listeriosis epizootic in sheep in New York state. Am J Vet Res 1997, 58:733-737.

46. Nightingale KK, Windham K, Martin KE, Yeung M, Wiedmann M: Select Listeria monocytogenes subtypes commonly found in foods carry distinct nonsense mutations in inIA, leading to expression of truncated and secreted internalin $A$, and are associated with a reduced invasion phenotype for human intestinal epithelial cells. Appl Environ Microbiol 2005, 71:8764-8772.

47. Roche SM, Gracieux P, Milohanic E, Albert I, Virlogeux-Payant I, Temoin S, Grepinet O, Kerouanton A, Jacquet C, Cossart P, Velge P: Investigation of specific substitutions in virulence genes characterizing phenotypic groups of low-virulence field strains of Listeria monocytogenes. Appl Environ Microbiol 2005, 71:6039-6048.

48. Buchrieser C, Rusniok C, Kunst F, Cossart P, Glaser P: Comparison of the genome sequences of Listeria monocytogenes and Listeria innocua: clues for evolution and pathogenicity. FEMS Immunol Med Microbiol 2003, 35:207-2I 3.

49. Glaser P, Frangeul L, Buchrieser C, Rusniok C, Amend A, Baquero F, Berche P, Bloecker H, Brandt P, Chakraborty T, Charbit A, Chetouani F, Couve E, de Daruvar A, Dehoux P, Domann E, Dominguez-Bernal G, Duchaud E, Durant L, Dussurget O, Entian KD, Fsihi H, Garcia-del Portillo F, Garrido P, Gautier L, Goebel W, Gomez-Lopez N, Hain T, Hauf J, Jackson D, Jones LM, Kaerst U, Kreft J, Kuhn M, Kunst F, Kurapkat G, Madueno E, Maitournam A, Vicente JM, Ng E, Nedjari H, Nordsiek G, Novella S, de Pablos B, Perez-Diaz JC, Purcell R, Remmel B, Rose M, Schlueter T, Simoes N, Tierrez A, Vazquez-Boland JA, Voss $\mathrm{H}$, Wehland J, Cossart P: Comparative genomics of Listeria species. Science 200I, 294:849-852

50. Doumith M, Cazalet C, Simoes N, Frangeul L, jacquet C, Kunst F, Martin $\mathrm{P}$, Cossart $\mathrm{P}$, Glaser $\mathrm{P}$, Buchrieser $\mathrm{C}$ : New aspects regarding evolution and virulence of Listeria monocytogenes revealed by comparative genomics and DNA arrays. Infect Immun 2004, 72: I072-1083.

5I. Nelson KE, Fouts DE, Mongodin EF, Ravel J, DeBoy RT, Kolonay JF, Rasko DA, Angiuoli SV, Gill SR, Paulsen IT, Peterson J, White O, Nelson WC, Nierman W, Beanan MJ, Brinkac LM, Daugherty SC, Dodson 
RJ, Durkin AS, Madupu R, Haft DH, Selengut J, Van Aken S, Khouri H, Fedorova N, Forberger $\mathrm{H}$, Tran B, Kathariou S, Wonderling LD, Uhlich GA, Bayles DO, Luchansky JB, Fraser CM: Whole genome comparisons of serotype $4 b$ and $I / 2 a$ strains of the foodborne pathogen Listeria monocytogenes reveal new insights into the core genome components of this species. Nucleic Acids Res 2004, 32:2386-2395.

52. J Craig Venter Institute [http://cmr.jcvi.org/]

53. Nightingale KK, Milillo SR, Ivy RA, Ho AJ, Oliver HF, Wiedmann M: Listeria monocytogenes F2365 carries several authentic mutations potentially leading to truncated gene products, including inlB, and demonstrates atypical phenotypic characteristics. J Food Prot 2007, 70:482-488.

54. Enright AJ, Van Dongen S, Ouzounis CA: An efficient algorithm for large-scale detection of protein families. Nucleic Acids Res 2002, 30:1575-1584

55. Thompson JD, Higgins DG, Gibson T]: CLUSTAL W: improving the sensitivity of progressive multiple sequence alignment through sequence weighting, position-specific gap penalties and weight matrix choice. Nucleic Acids Res 1994, 22:4673-4680.

56. Hall TA: BioEdit: a user-friendly biological sequence alignment editor and analysis program for Windows 95/98/NT. Nucl Acids Symp Ser 1999, 41 :95-98.

57. Rice P, Longden I, Bleasby A: EMBOSS: the European Molecular Biology Open Software Suite. Trends Genet 2000, 16:276-277.

58. Dieterich G, Karst U, Fischer E, Wehland J, Jansch L: LEGER: knowledge database and visualization tool for comparative genomics of pathogenic and non-pathogenic Listeria species. Nucleic Acids Res 2006, 34:D402-406.

59. Yang Z: PAML: a program package for phylogenetic analysis by maximum likelihood. Comput Appl Biosci 1997, 13:555-556.

60. Wong WS, Yang Z, Goldman N, Nielsen R: Accuracy and power of statistical methods for detecting adaptive evolution in protein coding sequences and for identifying positively selected sites. Genetics 2004, 168:104I-105I.

61. Zhang J, Nielsen R, Yang Z: Evaluation of an Improved BranchSite Likelihood Method for Detecting Positive Selection at the Molecular Level. Mol Biol Evol 2005, 22:2472-9.

62. Yang Z, Nielsen R, Goldman N, Pedersen AM: Codon-substitution models for heterogeneous selection pressure at amino acid sites. Genetics 2000, I55:43 I-449.

63. Sawyer SA: GENECONV: A computer package for the statistical detection of gene conversion. 1999 [http:// www.math.wustl.edu/\%7Esawyer/geneconv/]. Distributed by the author, Department of mathematics, Washington University in St louis

64. Bruen TC, Philippe H, Bryant D: A simple and robust statistical test for detecting the presence of recombination. Genetics 2006, I72:2665-268|.

65. Didelot $X$, Falush D: Inference of bacterial microevolution using multilocus sequence data. Genetics 2007, I75:|25I-| 266.

66. Benjamini $Y$, Hochberg Y: Controlling the false discovery rate: $a$ practical and powerful approach to multiple testing. Journal of the Royal Statistical Society B 1995, 57:289-300.

67. Storey JD, Tibshirani R: Statistical significance for genomewide studies. Proc Natl Acad Sci USA 2003, I00:9440-9445.

68. O'Neil HS, Marquis H: Listeria monocytogenes flagella are used for motility, not as adhesins, to increase host cell invasion. Infect Immun 2006, 74:6675-668I.

69. Horton RM, Cai ZL, Ho SN, Pease LR: Gene splicing by overlap extension: tailor-made genes using the polymerase chain reaction. Biotechniques 1990, 8:528-535.

70. Gouy M, Gautier C: Codon usage in bacteria: correlation with gene expressivity. Nucleic Acids Res 1982, 10:7055-7074.

7I. Carbone A, Kepes F, Zinovyev A: Codon bias signatures, organization of microorganisms in codon space, and lifestyle. Mol Biol Evol 2005, 22:547-561.

72. Willenbrock $H$, Ussery DW: Prediction of highly expressed genes in microbes based on chromatin accessibility. BMC Mol Biol 2007, 8: I I.

73. Wiuf C, Christensen T, Hein J: A simulation study of the reliability of recombination detection methods. Mol Biol Evol 200I, I 8:1929-1939.

74. Wehmhoner D, Dieterich G, Fischer E, Baumgartner M, Wehland J, Jansch L: "LaneSpector", a tool for membrane proteome profiling based on sodium dodecyl sulfate-polyacrylamide gel electrophoresis/liquid chromatography-tandem mass spectrometry analysis: application to Listeria monocytogenes membrane proteins. Electrophoresis 2005, 26:2450-2460.

75. Pamer EG: Direct sequence identification and kinetic analysis of an MHC class I-restricted Listeria monocytogenes CTL epitope. J Immunol 1994, I 52:686-694.

76. Sijts AJ, Neisig A, Neefjes J, Pamer EG: Two Listeria monocytogenes CTL epitopes are processed from the same antigen with different efficiencies. J Immunol 1996, I 56:683-692.

77. Lenz LL, Dere B, Bevan MJ: Identification of an H2-M3-restricted Listeria epitope: implications for antigen presentation by $M 3$. Immunity 1996, 5:63-72

78. Princiotta MF, Lenz LL, Bevan MJ, Staerz UD: H2-M3 restricted presentation of a Listeria-derived leader peptide. J Exp Med 1998, 187:17|I-1719.

79. Gulden PH, Fischer P 3rd, Sherman NE, Wang W, Engelhard VH, Shabanowitz J, Hunt DF, Pamer EG: A Listeria monocytogenes pentapeptide is presented to cytolytic $\mathrm{T}$ lymphocytes by the $\mathrm{H2}$ M3 MHC class Ib molecule. Immunity 1996, 5:73-79.

80. Pamer EG, Wang CR, Flaherty L, Lindahl KF, Bevan MJ: H-2M3 presents a Listeria monocytogenes peptide to cytotoxic T lymphocytes. Cell 1992, 70:215-223.

8I. Sanderson S, Campbell DJ, Shastri N: Identification of a CD4+ T cell-stimulating antigen of pathogenic bacteria by expression cloning. J Exp Med 1995, I 82:175I-I757.

82. Campbell DJ, Shastri N: Bacterial surface proteins recognized by CD4+ T cells during murine infection with Listeria monocytogenes. J Immunol 1998, 161:2339-2347.

83. Sanchez-Campillo M, Dramsi S, Gomez-Gomez JM, Michel E, Dehoux P, Cossart P, Baquero F, Perez-Diaz JC: Modulation of DNA topology by flaR, a new gene from Listeria monocytogenes. Mol Microbiol 1995, | 8:801-81।.

84. Goerke C, Wirtz C, Fluckiger U, Wolz C: Extensive phage dynamics in Staphylococcus aureus contributes to adaptation to the human host during infection. Mol Microbiol 2006, 6I: 1673-1685.

85. Li M, Kotetishvili M, Chen Y, Sozhamannan S: Comparative genomic analyses of the vibrio pathogenicity island and cholera toxin prophage regions in nonepidemic serogroup strains of Vibrio cholerae. Appl Environ Microbiol 2003, 69:1728-1738.

86. Anisimova M, Nielsen R, Yang Z: Effect of recombination on the accuracy of the likelihood method for detecting positive selection at amino acid sites. Genetics 2003, 164:1229-1236.

87. Meinersmann RJ, Phillips RW, Wiedmann M, Berrang ME: Multilocus sequence typing of Listeria monocytogenes by use of hypervariable genes reveals clonal and recombination histories of three lineages. Appl Environ Microbiol 2004, 70:2193-2203.

88. Nightingale KK, Schukken YH, Nightingale CR, Fortes ED, Ho AJ, Her Z, Grohn YT, McDonough PL, Wiedmann M: Ecology and transmission of Listeria monocytogenes infecting ruminants and in the farm environment. Appl Environ Microbiol 2004, 70:4458-4467.

89. Lappi VR, Thimothe J, Nightingale KK, Gall K, Scott VN, Wiedmann $M$ : Longitudinal studies on Listeria in smoked fish plants: impact of intervention strategies on contamination patterns. I Food Prot 2004, 67:2500-25|4.

90. Hodgson DA: Generalized transduction of serotype $1 / 2$ and serotype 4b strains of Listeria monocytogenes. Mol Microbiol 2000, 35:312-323.

91. Brehm K, Ripio MT, Kreft J, Vazquez-Boland JA: The bvr locus of Listeria monocytogenes mediates virulence gene repression by beta-glucosides. J Bacteriol 1999, 1 81:5024-5032.

92. Dalet K, Cenatiempo Y, Cossart P, Hechard Y: A sigma(54)dependent PTS permease of the mannose family is responsible for sensitivity of Listeria monocytogenes to mesentericin YI05. Microbiology 200I, I47:3263-3269.

93. Gravesen A, Ramnath M, Rechinger KB, Andersen N, Jansch L, Hechard Y, Hastings JW, Knochel S: High-level resistance to class Ila bacteriocins is associated with one general mechanism in Listeria monocytogenes. Microbiology 2002, 148:236I-2369.

94. Clark EE, Wesley I, Fiedler F, Promadej N, Kathariou S: Absence of serotype-specific surface antigen and altered teichoic acid glycosylation among epidemic-associated strains of Listeria monocytogenes. J Clin Microbiol 2000, 38:3856-3859.

95. Lan Z, Fiedler F, Kathariou S: A sheep in wolf's clothing: Listeria innocua strains with teichoic acid-associated surface antigens 
and genes characteristic of Listeria monocytogenes serogroup 4. J Bacteriol 2000, 182:6161-6168.

96. Promadej N, Fiedler F, Cossart P, Dramsi S, Kathariou S: Cell wall teichoic acid glycosylation in Listeria monocytogenes serotype $4 \mathrm{~b}$ requires gtcA, a novel, serogroup-specific gene. J Bacteriol 1999, 181:418-425.

97. Severino P, Dussurget $O$, Vencio RZ, Dumas E, Garrido P, Padilla G, Piveteau P, Lemaitre JP, Kunst F, Glaser P, Buchrieser C: Comparative transcriptome analysis of Listeria monocytogenes strains of the two major lineages reveals differences in virulence, cell wall and stress response. Appl Environ Microbiol 2007.

98. Lemon KP, Higgins DE, Kolter R: Flagellar motility is critical for Listeria monocytogenes biofilm formation. J Bacteriol 2007, 189:44|8-4424.

99. Bigot A, Pagniez H, Botton E, Frehel C, Dubail I, Jacquet C, Charbit A, Raynaud C: Role of FliF and Flil of Listeria monocytogenes in flagellar assembly and pathogenicity. Infect Immun 2005, 73:5530-5539.

100. Dons L, Eriksson E, Jin Y, Rottenberg ME, Kristensson K, Larsen CN, Bresciani J, Olsen JE: Role of flagellin and the two-component CheA/CheY system of Listeria monocytogenes in host cell invasion and virulence. Infect Immun 2004, 72:3237-3244.

101. Suerbaum S, Josenhans C: Helicobacter pylori evolution and phenotypic diversification in a changing host. Nat Rev Microbiol 2007, 5:44I-452.

102. Josenhans C, Eaton KA, Thevenot T, Suerbaum S: Switching of flagellar motility in Helicobacter pylori by reversible length variation of a short homopolymeric sequence repeat in fliP, a gene encoding a basal body protein. Infect Immun 2000, 68:4598-4603.

103. Kearns DB, Chu F, Rudner R, Losick R: Genes governing swarming in Bacillus subtilis and evidence for a phase variation mechanism controlling surface motility. Mol Microbiol 2004, 52:357-369.

104. Heichman KA, Johnson RC: The Hin invertasome: proteinmediated joining of distant recombination sites at the enhancer. Science 1990, 249:5II-5I7.

105. Jonquieres R, Bierne $H$, Mengaud J, Cossart P: The inlA gene of Listeria monocytogenes LO28 harbors a nonsense mutation resulting in release of internalin. Infect Immun 1998, 66:3420-3422.

106. Olier M, Pierre F, Lemaitre JP, Divies C, Rousset A, Guzzo ]: Assessment of the pathogenic potential of two Listeria monocytogenes human faecal carriage isolates. Microbiology 2002 , | 48: I855- I862.

107. Olier M, Pierre F, Rousseaux S, Lemaitre JP, Rousset A, Piveteau P, Guzzo J: Expression of truncated Internalin $A$ is involved in impaired internalization of some Listeria monocytogenes isolates carried asymptomatically by humans. Infect Immun 2003, 71:1217-1224

108. Rousseaux S, Olier M, Lemaitre JP, Piveteau P, Guzzo J: Use of PCRrestriction fragment length polymorphism of inlA for rapid screening of Listeria monocytogenes strains deficient in the ability to invade Caco-2 cells. Appl Environ Microbiol 2004 70:2180-2185
Publish with Biomed Central and every scientist can read your work free of charge

"BioMed Central will be the most significant development for disseminating the results of biomedical research in our lifetime. "

Sir Paul Nurse, Cancer Research UK

Your research papers will be:

- available free of charge to the entire biomedical community

- peer reviewed and published immediately upon acceptance

- cited in PubMed and archived on PubMed Central

- yours - you keep the copyright
BioMedcentral 